\title{
Biomimetic click assembled multilayer coatings exhibiting responsive properties
}

\author{
Maria P. Sousa $^{\mathrm{a}, \mathrm{b}, 1}$, Israel Gonzalez de Torre ${ }^{\mathrm{c}, \mathrm{d}}$, Mariana B. Oliveira ${ }^{\mathrm{a}, \mathrm{b}, 1}$, José C. Rodríguez-Cabello ${ }^{\mathrm{c}, \mathrm{e}}$, \\ João F. Mano ${ }^{\mathrm{a}, \mathrm{b}, *, 1}$ \\ a 3 's Research Group- Biomaterials, Biodegradables and Biomimetics, University of Minho, Headquarters of the European Institute of Excellence on Tissue Engineering and \\ Regenerative Medicine, AvePark, 4806-909 Taipas, Guimarães, Portugal \\ b ICVS/3B's - PT Government Associate Laboratory, Braga, Guimarães, Portugal \\ ${ }^{c}$ G.I.R. Bioforge, University of Valladolid, Edificio I+D, Paseo de Bel en, 1, 47011, Valladolid, Spain \\ d Technical Proteins Nanobiotechnology S.L., Valladolid, Spain \\ ${ }^{\mathrm{e}}$ Networking Research Center on Bioengineering, Biomaterials and Nanomedicine CIBER-BBN, Valladolid, Spain
}

\section{A R T I C L E IN F O}

\section{Article history:}

Received 12 January 2017

Received in revised form 6 April 2017

Accepted 6 April 2017

Available online $\mathrm{xxx}$

Keywords:

Elastin-like recombinamers

Click chemistry

Layer-by-layer

Stimuli-responsive

Myogenic differentiation

\begin{abstract}
A B S T R A C T
Stimuli-responsive polymers are capable of changing their physico-chemical properties in a dynamic way, to respond to variations on the surrounding environment. These materials have gained increasingly importance for different areas, such as drug delivery, biosensors, microelectronic systems and also for the design and modification of biomaterials to apply on tissue engineering field. In the last years, different strategies have been envisaged for the development of stimuli-responsive biomaterials. Layer-by-layer $(\mathrm{LbL})$ is a promising and versatile technique to modify biomaterials' surfaces, and has allowed tailoring interactions with cells. In this study, LbL is used to construct biomimetic stimuli-responsive coatings using elastin-like recombinamers (ELRs). The recombinant nature of ELRs provides the ability to introduce specific bioactive sequences and to tune their physicochemical properties, making them attractive for biomedical and biological applications. By using complementary clickable ELRs, we were able to construct multilayer coatings stabilized by covalent bonds, resulting from the Huisgen 1,3-dipolar cycloaddition of azides and alkynes. Herein, we exploited the switchable properties of the ELRs-based coatings which are dependent on lower critical solution temperature (LCST) transition. Above LCST, the polymers collapsed and nanostructured precipitates were observed on the surface's morphology, increasing the water contact angle. Also, the influence of $\mathrm{pH}$ on prompting reversible responses on coatings was evaluated. Finally, in vitro cell studies using a $\mathrm{C} 2 \mathrm{C} 12$ myoblastic cell line were performed to perceive the importance of having bioactive domains within these coatings. The effect of RGD incorporation is clearly noted not only in terms of adhesion and proliferation but also in terms of myoblast differentiation.
\end{abstract}

(C) 2016 Published by Elsevier Ltd.

\section{Introduction}

Scientists have been increasingly applying efforts to imitate materials, systems or elements present in Nature, in the pursue of solutions for some healthcare concerns. Particular focus has been given to bioinspired systems; for instance, a basic process of living systems is the ability to respond or adapt to different stimuli $[1,2]$. In these adaptation processes, different length scales can be considered; from molecular interactions triggering a cascade of cellular events like cell signaling, endocytosis and exocytosis, to macroscopic interactions with external stimuli like temperature, prompting cascades of nervous signals transmitted to the brain and causing a physiological response [3].

Therefore, developing polymeric materials capable of responding to environmental changes represents a challenge with high impact. Different stimuli, such as temperature, $\mathrm{pH}$, chemical composition, mechanical forces or even light or magnetic abilities, can trigger morphological, chemical and physical changes on polymeric materials,

\footnotetext{
* Corresponding author. ICVS/3B's - PT Government Associate Laboratory, Braga, Guimarães, Portugal.

Email address: jmano@ua.pt (J.F. Mano)

${ }^{1}$ Current address: Department of Chemistry, CICECO, University of Aveiro, 3810-193 Aveiro, Portugal.
}

[3-5]. A diversity of architectures, from 2-dimensional to 3-dimensional, has been suggested to develop stimuli-responsive systems. Examples include thin films [6,7], membranes [8,9], nanoparticles $[10,11]$, gels or even capsules [10]. A wide-range of techniques has been employed to produce such kind of architectures, and LbL appeared as one of the strongest candidates to fabricate structures with distinct geometries [12]. It is an inexpensive and versatile tool for biomaterials surface modification and has allowed tailoring cell-material interactions [13-15]. Intermolecular interactions are in the base of LbL methodology, with electrostatic forces assuming a major role [16]; typical LbL is mainly based on the deposition of oppositely charged polyelectrolytes. However, also non-electrostatic forces can be involved [17]; van der Waals, hydrogen, coordination and covalent bonds are some of them. In recent years, significant increase of stability has been reported when considering covalent bonds as the major player on the LbL construction $[18,19]$. For instance, Seo J. et al. [20] developed multifunctional polymer multilayer thin films with good physicochemical stability using the LbL deposition based on covalent bonds between activated esters and amine groups. Other strategies based on covalent interactions have been suggested. Click chemistry based LbL was reported to produce ultrathin films on silica particles, developing $\mathrm{pH}$-responsive click capsules [21]. Herein, we take advantage of a catalyst-free click technology, in which specific 
interactions are a result from Huisgen 1,3-dipolar cycloaddition of azides and alkynes [22,23].

Nowadays, polymeric materials have been the most studied class to produce LbL nanostructured assemblies, either being of synthetic or natural origin [12]. Polysaccharides [24,25], proteins [26-28] and even DNA [29] have been explored. Using LbL methodology, Costa R. et al. [26] produced responsive thin multilayer coatings based on electrostatic interactions assembly of chitosan and elastin-like recombinamers (ELRs). Recombinant elastin has been reported as biocompatible, with mechanical properties comparable to those of native human elastin and with a thermosensitive behavior dependent of their lower critical solution temperature (LCST) [26,30,31].

In this study, we propose the production of stable thin coatings to be used in biomedicine, combining ELRs with LbL technology and click chemistry. Taking advantage of recombinant technologies, different ELRs were synthetized. This technology allows to introduce specific bioactive moieties and tailor physicochemical and bioactive properties of the polymers, making them attractive for biomedical and tissue engineering proposes. Therefore, we investigate the responsive abilities of these coatings and the influence of having the arginine-glycine-aspartic acid (RGD) motif on the chemical structure of the coatings. The presence of RGD tripeptide has gained particular interesting due to its well-known support to cellular adhesion $[26,32,33]$.

We hypothesize that the presence of RGD motifs on the surface of the films can be of extreme relevance to apply those kind of films towards tissue engineering strategies or in the design of new microenvironments for cell culture.

\section{Experimental section}

\subsection{Materials}

The bioproduction, purification and chemical modification of the different clickable ELRs (cyclooctyne- and azide-modified ELRs) can be found elsewhere [34]. Low glucose Dulbecco's modified Eagle's medium (DMEM) without phenol red and sodium bicarbonate and DMEM with phenol red were purchased as powder from Sigma-Aldrich, as well as the sodium bicarbonate, sodium acetate trihydrate, PBS tablets, 4',6-Diamidine-2'-phenylindole dihydrochloride (DAPI), Phalloidin-Tetramethylrhodamine B isothiocyanate, Triton $\times 100$ and bovine serum albumin (BSA). Sodium hydroxide $(\mathrm{NaOH})$ was purchased from Fisher Scientific and glacial acetic acid from VWR. The glass coverslips (13 mm diameter) were provided by Agar Scientific (UK). Fetal bovine serum (FBS), penicillin-streptomycin, Alexa Fluor 488, and DPBS (PBS without calcium and magnesium) were supplied by Life Technologies. CellTiter $96^{\circledR}$ Aqueous One Solution was purchased from Promega, horse serum (New Zealand origin) from Invitrogen and skeletal muscle troponin $\mathrm{T}$ antibody from Acris Antibodies.

\subsection{Bioproduction of the ELRs}

Genetic engineering techniques were used to synthetize the ELRs of interest, following a procedure already described elsewhere [34]. The obtained ELRs were purified, dialyzed and then lyophilized. In the end, two ELRs were used: the ELR HRGD6, which contains the adhesion sequence RGD and the ELR VKVx24, which contains a similar structure to the first one but without the bioactive sequence. To allow the click chemistry reaction, reactive groups were required; for that, the bioproduced ELRs were chemically modified at their lysine amino acids by transformation of the $\varepsilon$-amine group present in the lateral chain of the lysine residue. This process was achieved with a relatively mild and easy-to-perform reactions. A diazo transfer reaction to amines was performed on the two different ELRs, in order to introduce azides directly at the lysine positions of proteins, following a methodology described before [34]. The resulting azide conversion was in the order of $70-90 \%$ of substitution and the two working ELRs were, thus, chemically modified: VKV-N $\mathrm{N}_{3}$ and RGD-N $\mathrm{N}_{3}$. Also alkyne cyclooctyne groups were introduced at the lysine positions of proteins with a substitution degree in the order of $60 \%$, following a procedure already described [34]. From cyclooctyne modification we obtained the clickable ELRs: VKV-cyclo.

\subsection{Size distribution and zeta potential measurement of the polymeric solutions}

The modified ELRs solutions were prepared in serum-free DMEM without phenol red at $0.5 \mathrm{mg} \mathrm{ml}^{-1}$. After that, the solutions were maintained overnight at different temperatures: $4{ }^{\circ} \mathrm{C}$, room temperature (RT, $20^{\circ} \mathrm{C}$ ) and $37^{\circ} \mathrm{C}$. The single size distribution of the prepared solutions was then measured through dynamic light scattering (DLS), using a Nano-ZS equipment from Malvern (United Kingdom). The measurements were made in the equipment at $4{ }^{\circ} \mathrm{C}$, RT and $37^{\circ} \mathrm{C}$, accordingly to the different overnight incubations.

ELR solutions were prepared at same concentrations, and their $\mathrm{pH}$ was adjusted to $6.5,7.0$ or 7.5 using $\mathrm{NaOH} 1 \mathrm{M}$ and acetic acid $1 \%$ $(\mathrm{v} / \mathrm{v})$. The zeta $(\zeta)$-potential of the different solutions were also determined using a Nano-ZS equipment from Malvern.

\subsection{Build-up kinetics construction}

A quartz crystal microbalance with dissipation monitoring system (QCM-D, Q-Sense, Sweden) was used to follow up the absorption of the ELRs above crystal gold-coated crystals. ELRs solutions were prepared at concentrations of $0.5 \mathrm{mg} \mathrm{ml}^{-1}$ in serum-free DMEM without phenol red, $\mathrm{pH}$ of 7 . This water-based solvent was used as washing solution. The multilayer construction of combinations of (i) VKV-cyclo with RGD-N $\mathrm{N}_{3}$ and (ii) VKV-cyclo with VKV-N $\mathrm{N}_{3}$ was investigated for the deposition of 4 bilayers. Each polymer solution was pumped during 20 min with washing steps between each layer (15 min). The working temperature was defined as RT and the flow rate as $50 \mu \mathrm{min}^{-1}$. The thickness of the multilayer films was estimated based on the Voigt model [35], using the Q-tools software (Q-Sense, Sweden).

\subsection{Assembly of ELRs clickable multilayers}

Glass coverslips were cleaned with 5 min cycles of acetone, ethanol and isopropanol (all from Sigma-Aldrich) in a ultrasonication bath and activated using an UV-Ozone Cleaner (ProCleaner 220, Bioforce Nanoscience) during $10 \mathrm{~min}$. The polymer solutions were prepared at concentrations of $0.5 \mathrm{mg} \mathrm{ml}^{-1}$ in serum-free DMEM without phenol red and sodium bicarbonate, $\mathrm{pH}$ of 7 . Different formulations were produced; the combination of VKV-cyclo with RGD-N and VKV-cyclo with VKV-N 3 . For both, we started adsorbing the cyclooctyne-modified ELR during $20 \mathrm{~min}$, followed by a washing step with serum-free DMEM. Then the click reaction was completed introducing the azide-modified polymers, through the immersion of the surfaces in the RGD- $\mathrm{N}_{3}$ or $\mathrm{VKV}-\mathrm{N}_{3}$, again during $20 \mathrm{~min}$ and then a quick washing step. The process was repeated four times, at RT, in order to form a 4 bilayer elastin-based film. Note that, in between each incubation time, the solutions were maintained at $4{ }^{\circ} \mathrm{C}$. In the 
end, two click assembled multilayer coatings were obtained: i) $\left(\left(\mathrm{VKV} \text { - cyclo/RGD- } \mathrm{N}_{3}\right)_{4}\right.$ and ii) $\left(\mathrm{VKV} \text {-cyclo/VKV- } \mathrm{N}_{3}\right)_{4}$.

\subsubsection{Fluorescence microscopy}

Fluorescence microscopy was used to investigate the effectiveness of the coating process. The addition of fluorescent probes to ELRs was described elsewhere [34]. Acetylene Fluor 488 was added to azide modified ELRs, providing them with fluorescence. Labelled ELRs were used to construct the ELR-based multilayers at RT, instead of using the non-fluorescent forms. After 4 bilayers, the (VKV- cyclo/ RGD- $\left.\mathrm{N}_{3}\right)_{4}$ and $\left(\mathrm{VKV} \text {-cyclo/VKV- } \mathrm{N}_{3}\right)_{4}$ films were dried at RT, protected from light and visualized under transmitted and reflected light microscope with apotome 2 (Axio Imager Z1m, Zeiss, Germany).

\subsection{2. $A F M$}

Atomic force microscopy (AFM) was used to investigate the topography of the multilayer-coated surfaces. These studies were performed using AFM equipment (Dimension Icon, Bruker, USA) operated in a tapping mode at a frequency of $1 \mathrm{~Hz}$. The samples were immersed in PBS during $30 \mathrm{~min}$ and their topography was evaluated at RT, with an analyzed area of $5 \times 5 \mu \mathrm{m}^{2}$. Coatings performed with 1 bilayer and 4 bilayers of (VKV- cyclo/RGD- $\mathrm{N}_{3}$ ) and (VKV-cyclo/VKV- $\mathrm{N}_{3}$ ) coatings were imaged. Values of arithmetic averaged roughness $\left(\mathrm{R}_{a}\right)$ surface were determined analyzing 5 samples of each condition.

\subsection{Stimuli-responsive properties investigation}

\subsubsection{SEM}

Scanning electron microscopy (SEM) was used to investigate the morphology of the resulting multilayer-coated surfaces. Surface micrographs were obtained using a high-resolution field emission SEM with focused ion beam (Auriga Compact, Zeiss, Germany). (VKV-cyclo/RGD-N $)_{4}$ and $(\mathrm{VKV} \text {-cyclo/VKV-N })_{4}$ coatings, produced at $\mathrm{RT}$, were observed after overnight incubations at different temperatures: $4{ }^{\circ} \mathrm{C}$, RT and $37^{\circ} \mathrm{C}$. Prior to observation the samples were dried and coated with platinum using a sputter coater (EM ACE 600, Leica, Austria).

\subsection{2. $W C A$}

The water contact angle (WCA) of the elastin-coated surfaces was investigated to study the influence of the temperature and the $\mathrm{pH}$ on their wettability. The WCA values were measured using a OCA20 system (DataPhysics, Germany). WCA of cleaned glass coverslips, $(\mathrm{VKV} \text {-cyclo/RGD-N })_{4}$ and $(\mathrm{VKV} \text {-cyclo/VKV-N })_{4}$ coatings, obtained at RT, were investigated firstly at RT and then for repeating cycles of temperatures of $37^{\circ} \mathrm{C}$ and $4{ }^{\circ} \mathrm{C}$. This was possible using a liquid temperature control unit (TFC 100, DataPhysics, Germany), which could be coupled with OCA20 system and linked to a temperature-controlled bath system. This system allowed a protective atmosphere to surround the sample working area, maintaining temperature and humidity homogeneously distributed over working area. The cycle temperatures were continuously repeated 10 times in order to evaluate the reversibility of the temperature responsiveness of elastin-coated surfaces.

The $\mathrm{pH}$ responsiveness of the surfaces was also investigated. WCA measurements were made after sample immersion at working $\mathrm{pH} 7$. Then, the elastin-based surfaces were submitted to sequential immersions on different $\mathrm{pH}$ solutions, wherein after each 60-min immersion the samples were withdraw and the WCA measured. Basically, acid and alkaline sodium acetate solutions were prepared at a
$150 \mathrm{mM}$ concentration; the samples were sequentially and continuously immersed in solutions with $\mathrm{pH}$ values of $4,10,3,11,2$ and 12.

\subsubsection{Cascade of $p H$ effect after film construction}

QCM-D analysis was performed to investigate the influence in situ of acidic and alkaline cascades after the film construction. The procedure described for the build-up kinetics construction was repeated. After the film build-up, the elastin multilayers were flushed with acidic or alkaline sodium acetate solutions, where the $\mathrm{pH}$ was adjusted using appropriated volumes of $\mathrm{NaOH}(0.5 \mathrm{M})$ and acetic acid $(2 \%(\mathrm{v} / \mathrm{v}))$. These solutions were injected into the system for $30 \mathrm{~min}$, followed by a short injection with a sodium acetate solution at $\mathrm{pH} 7$ to evaluate the reversibility of the process. The influence of the $\mathrm{pH}$ on the elastin multilayers was evaluated by varying the $\mathrm{pH}$ in a cyclic way in an acidic range $(\mathrm{pH} \mathrm{4,} \mathrm{pH} 3$ and $\mathrm{pH} 2)$ and, also, in an alkaline range $(\mathrm{pH} 10$, $\mathrm{pH} 11$ and $\mathrm{pH}$ 12). The respective frequency and dissipation changes were recorded in real time.

\subsection{Cellular in vitro studies}

Cell studies were performed onto elastin-coated surfaces (surface area around $133 \mathrm{~mm}^{2}$ ) using $\mathrm{C} 2 \mathrm{C} 12$ myoblast cell line (ATCC, CRL-1772). This cell line is a mouse myoblast cell line which has already been well-characterized on literature [36], presenting some interesting features; these cells can rapidly differentiate into myotubes, expressing different characteristic muscle proteins and being a well-known model to study in vitro cell differentiation. Tissue culture polystyrene surfaces (TCPS) were used as positive control and clean and activated glass coverslips as reference control. The cells were cultured at passages 5,6 and 7 on $150 \mathrm{~cm}^{3}$ flasks and maintained in culture with DMEM with phenol red supplemented with $10 \%$ fetal bovine serum (FBS) and 1\% penicillin/streptomycin, until achieving 65/70\% confluence. Then, the cells were enzymatically detached from the flasks using TrypleExpress (Life Technologies TM) and seeded on the surfaces at a density of $2.0 \times 10^{4}$ cells per sample, by dropping $200 \mu \mathrm{l}$ of the cell suspension right above the samples. The samples were incubated at $37^{\circ} \mathrm{C}$ and $5 \% \mathrm{CO}_{2}$. After $3 \mathrm{~h}, 1 \mathrm{ml}$ of culture medium was added to each sample. The cells coated on the samples were analyzed at different time points, using the methodologies described below.

\subsubsection{Cellular metabolic activity}

C2C12 were seeded on $13 \mathrm{~mm}$ diameter circular glass coverslips uncoated and coated with modified ELRs and incubated for 1,2 and 5 days. The respective metabolic activity was evaluated using MTS (3-(4,5-dimethylthiazol-2-yl)-5-(3-carboxymethoxyphenyl)-2-(4-sulfophenyl)-2H-tetrazolium) reagent (Promega), according with the manufacturer's instructions. The cells adhered to the elastin-based coatings were washed with sterile DPBS and incubated with $500 \mu$ of a 4:1 mixture of serum-free DMEM and MTS reagent. The samples were incubated at $37{ }^{\circ} \mathrm{C}$ and $5 \% \mathrm{CO}_{2}$ during $3 \mathrm{~h}$ and, after this time, the absorbance was read at $490 \mathrm{~nm}$ using a microplate reader (Synergy HT, BioTek). The blank values of absorbance for the materials incubated without cells were subtracted to the absorbance values when in presence of the cells.

\subsubsection{Cellular proliferation}

Cell proliferation assay was performed using a double stranded DNA (dsDNA) quantification kit (Picogreen ${ }^{\circledR}$, Invitrogen). C2C12 cells seeded above the elastin-coated surfaces and incubated for 1,2 and 5 days of culture were washed twice with DPBS and transferred into Eppendorf tubes containing $1 \mathrm{ml}$ of ultra-pure water. 
The samples were left to incubate for $1 \mathrm{~h}$ at $37^{\circ} \mathrm{C}$ and $5 \% \mathrm{CO}_{2}$ humidified atmosphere and then frozen at $-80^{\circ} \mathrm{C}$ until analysis. For the DNA quantification, the samples were thawed and sonicated for $20 \mathrm{~min}$. The DNA standards were prepared at concentrations $0 \mu \mathrm{ml}^{-1}, 0.2 \mu \mathrm{ml}^{-1}$, $0.5 \mu \mathrm{ml}^{-1}, 1 \mu \mathrm{ml}^{-1}$ and $1.5 \mu \mathrm{ml}^{-1}$. The reacting reagent, TE buffer and the samples were added in triplicate to a 96-well opaque plate (Falcon). The fluorescence was measured using a microplate reader, with an excitation wavelength of $480 \mathrm{~nm}$ and an emission wavelength of $528 \mathrm{~nm}$. For each sample, the DNA concentration was calculated using a standard curve that relates DNA concentration with fluorescence intensity.

\subsubsection{Cellular morphology}

At 1,2 and 5 days of cell culture, $\mathrm{C} 2 \mathrm{C} 12$ cells seeded on the elastin-coated and TCPS were washed with DPBS and then fixed with formalin $10 \%((\mathrm{v} / \mathrm{v})$ in DPBS $)$ during $30 \mathrm{~min}$ at $4{ }^{\circ} \mathrm{C}$. The fixed samples were then stained with rhodamine phalloidin (1:200 in DPBS) for cellular F-actin, and DAPI (1:1000 in DPBS) for cell nuclei. A transmitted and reflected light microscope with apotome 2 (Axio Imager $\mathrm{Z1m}$, Zeiss, Germany) was used to image the stained cells.

\subsubsection{Myogenic differentiation}

To evaluate the potential of the developed coatings to allow myogenic differentiation, $\mathrm{C} 2 \mathrm{C} 12$ cells were seeded at $1.5 \times 10^{4}$ cells per sample on the ELR-coated and uncoated glass coverslips, following the same procedure described before. The cells were maintained at $37{ }^{\circ} \mathrm{C}$ and $5 \% \mathrm{CO}_{2}$ in DMEM culture medium. When $90 \%$ of confluence was achieved, the culture medium was exchanged by differentiation medium, composed of DMEM supplemented with $2 \%$ of horse serum and $1 \%$ of antibiotics/antimicotics, to induce cell differentiation. After one week, the cells were stained by an immunocytochemistry protocol to identify troponin T-positive cells. After fixing the cells with formalin $10 \%(\mathrm{v} / \mathrm{v})$, the samples were washed and permeabilized with $1 \%$ Triton $\times 100((\mathrm{v} / \mathrm{v})$ in DPBS $)$ and blocked with $0.1 \%$ of BSA. After washing with DPBS, the samples were incubated overnight at $4{ }^{\circ} \mathrm{C}$ with the mouse troponin $\mathrm{T}$ antibody (1:100 in DPBS) and after this time the samples were washed and incubated with the secondary antibody anti-mouse Alexa Fluor 488 (1:800 in DPBS) during $1 \mathrm{~h}$ at RT. Then the cells were incubated with DAPI $(1: 1000$ in DPBS) to counterstain the nuclei. The samples were then extensively washed with DPBS to remove the excess of fluorescence probes. A transmitted and reflected light microscope with apotome 2 was used to image the stained cells.

\subsubsection{Morphometric parameters}

Different morphometric parameters can be determined from the immunofluorescence images; fusion index and average number of troponin T-positive myotubes per area were determined using ImageJ (National Institute of Health, USA) tools. A cell containing 3 or more nuclei was considered a myotube. The fusion index was calculated, as the ratio of the nuclei number within the troponin T-positive myotubes versus the total number of nuclei in the same area. Also, the average of myotubes area, perimeter, length and elongation factor were determined using ImageJ tools. The elongation factor describes to what extent the equimomental ellipse is lengthened or stretched out [37].

\subsection{Statistical analysis}

Unless referred, all quantitative results were obtained in triplicated and considered as mean \pm standard deviation (SD). Statistical analysis was done with the help of GraphPad 6.0 software, using the one -way analysis of variance (ANOVA) with Bonferroni post-test multiple comparison; differences were considered statistically significant with a p value less than $0.05,0.01$ and 0.001 .

\section{Results and discussion}

\subsection{Size distribution and zeta potential measurements}

ELRs have been explored for biomedical applications [38-40] due, not only to the ability of tailoring amino acid contents, mechanical stiffness and degradation ratio, but also its thermoresponsive properties. The proposed ELRs were obtained using genetic engineering in E. choli; whose bioproduction, purification and modification are well established [41]; the proton nuclear magnetic resonance (NMR), the Fourier transform infrared spectroscopy (FTIR) and the differential scanning calorimetry (DSC) spectra were collected for each modified ELR (VKV-cyclo, RGD-N 3 and VKV-N ${ }_{3}$ ) [34]. For the present investigation, DCS results had particular interest since these materials could present different behaviors below and above LCST This important parameter was already investigated for these modified ELRs, using water as solvent [34]. The cyclooctyne modified VKV (VKV-cyclo) presented LCST around $15^{\circ} \mathrm{C}$; the azide modified RGD (RGD-N3) and VKV (VKV-N3) showed LCST around $21^{\circ} \mathrm{C}$ and $24^{\circ} \mathrm{C}$, respectively [34]. Besides we used a water-based solvent, DMEM is composed of salts, which can slightly change the LCST values. Nonetheless we used these values as reference. Size and zeta potential measurements were carried out to perceive if some changes in ELR aggregates size or net charge happen with temperature or $\mathrm{pH}$ variation.

Size measurements of the structures in solution were carried out for each ELR - see Fig. 1A. These measurements were made at $4{ }^{\circ} \mathrm{C}$, which is far below the reported LCST, RT, which is close to LCST, and $37{ }^{\circ} \mathrm{C}$, which is far above LCST. At $4{ }^{\circ} \mathrm{C}$, moderate polydispersity was found for $\mathrm{VKV}$-cyclo (Pdi $=0.5 \pm 0.05), \mathrm{RGD}^{-\mathrm{N}_{3}}$ $(\mathrm{Pdi}=0.5 \pm 0.06)$ and $\mathrm{VKV}-\mathrm{N}_{3}(\mathrm{Pdi}=0.6 \pm 0.15)$. The size distribution of VKV-cyclo was about $128 \pm 59.6 \mathrm{~nm}$; similar size distributions were obtained for RGD-N $\mathrm{N}_{3}$ and VKV-N $\mathrm{N}_{3}(150 \pm 80.1 \mathrm{~nm}$ and $208 \pm 15.9 \mathrm{~nm}$, respectively). At RT, ELRs polydispersion slightly increased $(\mathrm{Pdi}=0.6 \pm 0.18$ for $\mathrm{VKV}$-cyclo). The single size distribution of the different ELRs also increased; the single size distribution for VKV-cyclo was about $320 \pm 125.6 \mathrm{~nm}$ while for azide-modified ELRs was about $425 \pm 82.8 \mathrm{~nm}$ for RGD-N 3 and $258 \pm 45.4 \mathrm{~nm}$ for $\mathrm{VKV}-\mathrm{N}_{3}$. At $37^{\circ} \mathrm{C}$, we observed a significant increase on the size distribution of the different ELRs, with heterogeneous diameters found ( $\mathrm{Pdi}=0.5 \pm 0.04$ for $\mathrm{VKV}$-cyclo). $\mathrm{VKV}$-cyclo presents a single size distribution of $938 \pm 61.8 \mathrm{~nm}$ and a little bit lower values were obtained for azide-modified ELRs $(671 \pm 144.4 \mathrm{~nm}$ for RGD-N and $610 \pm 40.6 \mathrm{~nm}$ for $\left.\mathrm{VKV}-\mathrm{N}_{3}\right)$. The obtained results are consistent with the solubility in water-based solvents of the ELRs below LCST and their precipitation above the LCST. As described above, modified ELRs have a LCST close to RT. We believe that at RT occurs the transition phenomenon and the polymers start to collapse. Even so, and as we were working in the transition temperature range, the phase separation was not clearly visible yet and there was no significant differences on the size distribution results when compared with the ones obtained at $4{ }^{\circ} \mathrm{C}$. Below LCST, at $4{ }^{\circ} \mathrm{C}$, the ELRs solutions are hydrated and dispersed in the solvent, mainly in a linear form, while above LCST $\left(37^{\circ} \mathrm{C}\right)$ the polymer solutions started to precipitate in a folded globular organization with higher diameters $[34,42]$.

In order to perceive the best $\mathrm{pH}$ to construct the clickable elastin-based coatings, the $\zeta$-potentials of the different ELRs in solution

were 

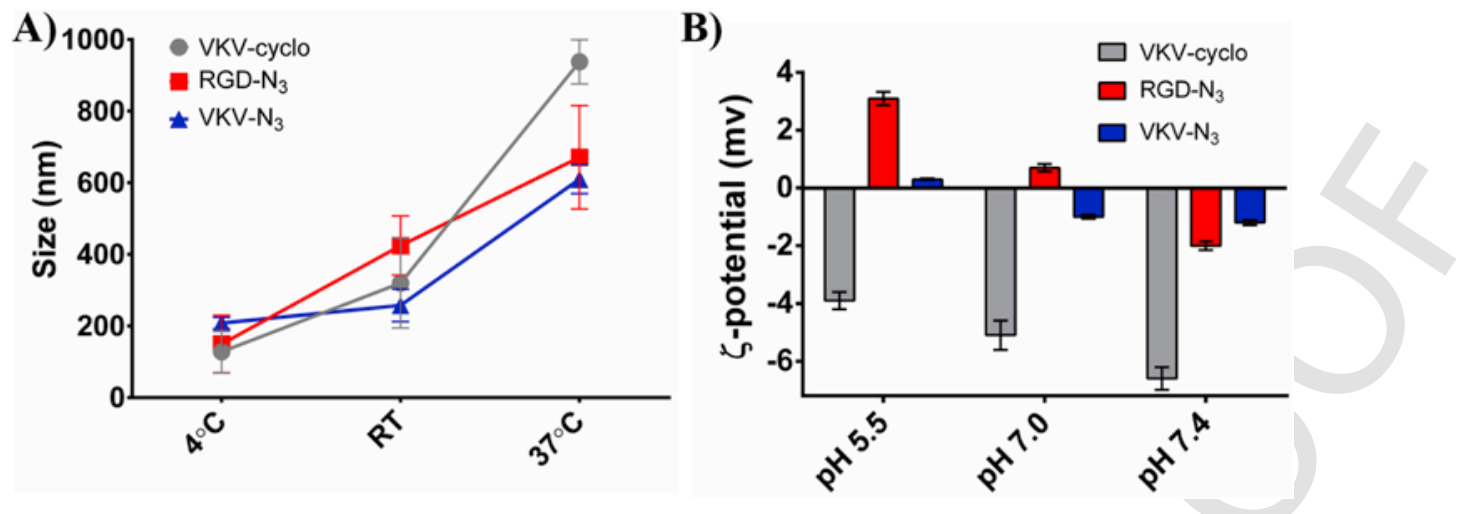

Fig. 1. Effect of temperature on A) zeta sizer and B) zeta potential of VKV-cyclo, RGD- $\mathrm{N}_{3}$ and $\mathrm{VKV}-\mathrm{N}_{3}$ solutions $(0.05 \%(\mathrm{w} / \mathrm{v}))$.

determined for different $\mathrm{pH}$ values, at RT - see Fig. 1B. For RGD-N and $\mathrm{VKV}-\mathrm{N}_{3}$ solutions, the decrease of $\mathrm{pH}$ implied the protonation of the solution. Besides the nature of ELRs being essentially hydrophobic, the proposed ELRs were designed to contain lysine residues, which have positively charged amine groups $[26,43]$. At $\mathrm{pH}$ below 7.0 , the RGD- $\mathrm{N}_{3}$ solution presented a $\zeta$-potential of $3.1 \pm 0.23 \mathrm{mV}$, being protonated and, naturally, positively charged. At higher $\mathrm{pH}$ values, the amine groups started to deprotonate and the $\zeta$-potential decreased to $-2.0 \pm 0.15 \mathrm{mv}$. When $\mathrm{pH}$ was equal to $7.0, \mathrm{RGD}_{3} \mathrm{~N}_{3}$ solution charge was closer to 0 ( $\zeta$-potential $=0.7 \pm 0.13 \mathrm{mv})$. The $\zeta$-potential of VKV-N $\mathrm{N}_{3}$ solutions presented similar behavior to RGD-N solutions, at the different $\mathrm{pH}$. Although the solutions were differently charged at $\mathrm{pH} 6.5$ and 7.5 , the differences between the respective $\zeta$-potentials were not significant. Overall, at $\mathrm{pH} 7.0$ the $\zeta$-potentials of the different azide solutions were closer to 0 and we hypothesize that the different ELRs were almost discharged. For this reason, we decided to construct the coatings at $\mathrm{pH} 7.0$ to minimize the effect of electrostatic interactions on the construction of the LbL-based coatings.

\subsection{Build-up kinetics construction}

After optimizing the working $\mathrm{pH}$ and temperature, the build-up of the elastin-based multilayers was assessed using QCM-D monitoring. Fig. 2A and $\mathrm{B}$ represents the frequency $\left(\Delta f_{n}\right)$ and dissipation $\left(\Delta D_{n}\right)$ variations at third overtone $(n=3)$ above a gold crystal, when flushed by the different ELRs solutions. These variations were monitored accordingly to the time of depositions. Two constructions were evaluated: the one containing the VKV-cyclo and the RGD-N ${ }_{3}$ (see Fig. $2 \mathrm{~A}$ ) and the other one containing the VKV-cyclo and the VKV-N (see Fig. 2B). The first six minutes correspond to the establishment of the baseline. In both graphs, the next 20 min show the deposition of the VKV-cyclo and the subsequent washing until removing the excess of polymer, which was not adsorbed at the surface. The following 20 min correspond to the RGD- $\mathrm{N}_{3}$ or the VKV-N $\mathrm{N}_{3}$ adsorptions. For both cases, $\Delta f_{3}$ decreased with time; this observation can be related with the time of deposition/adsorption of the polymers above the surface of the gold crystal. On the other hand, $\Delta D_{3}$ increased with time indicating that elastin-based films did not present a rigid behavior and started to dissipate energy. In fact, this non-rigid/viscoelastic behavior is common for macromolecular systems [44]. The subsequent steps show the same trend: the ELRs deposition was strong for the first layers but it decreased for the next ones. Within the multilayers construction, $\Delta f_{3}$ resultant of washing steps became smaller, showing that ELRs were strongly linked and formed a stable coating for the LbL build-up. As already referred above, at $\mathrm{pH} 7.0$ both azide
ELRs showed close to neutral zeta potential, and we hypothesize that there is no surface charge overcompensation by the formation of polycation-polyanion pairs. Therefore, we can consider the covalent bonding resulting from the click reaction (azide-alkyne cycloaddition) as the main force involved in the $\mathrm{LbL}$ construction. Four bilayers were constructed, with good indications of the effectiveness of the click chemistry reaction. A chemical scheme of this reaction is presented in Fig. 2C, where alkyne group links to azide group by means of a cycloaddition reaction, being the basis of the ELR-based film build-up. The first layer of VKV-cyclo was adsorbed to the substrates, allowing the further construction of the remaining layers through covalent linkage between cyclooctyne and azide groups, under mild aqueous conditions. Caruso's research group [45] used cycloaddition chemistry to build-up LbL multilayer systems by dipping different inert substrates into poly(acrylic acid) copolymerized with azide or alkyne groups. They further took advantage of this technology to fabricate $\mathrm{pH}$ responsive capsules that can serve as a versatile platform for further functionalization [21]. Other advantages were reported using such technology: producing high stable films, with no need of post cross-linking processes and with the possibility of incorporation of a wide range of functionalized materials $[19,46]$.

Other information could be attained from the QCM-D data. The estimated thickness of the elastin-based coatings was calculated based on the Voigt Model, using an appropriated software. The estimated thickness after each deposition was plotted over the number of layers. For both constructions (VKV-cyclo/RDG-N $\left.{ }_{3}\right)_{n}$ and $(\mathrm{VKV}$-cyclo/ $\left.\mathrm{VKV}-\mathrm{N}_{3}\right)_{n}$ (where $n$ represents the number of bilayers), the film growth showed a non-linear behavior - see Fig. 2D and E, respectively. We used a non-linear regression to generate a mathematical model which fits both (VKV-cyclo/RDG- $\left.\mathrm{N}_{3}\right)_{n}$ and (VKV-cyclo/VKV- $\left.\mathrm{N}_{3}\right)_{n}$ thickness growth. After 4 bilayers, the (VKV-cyclo/ RDG- $\left.\mathrm{N}_{3}\right)_{4}$ has an estimated thickness of $598 \pm 8.5 \mathrm{~nm}$, while the [VKV-cyclo/VKV- $\left.\mathrm{N}_{3}\right]_{4}$ presented an estimated thickness of $586 \pm 91.2 \mathrm{~nm}$. Taken a hyperbolic model as base, we hypothesize that after reaching the double of bilayers (16 layers), (VKV-cyclo/ RDG- $\left.\mathrm{N}_{3}\right)_{4}$ will present an estimated thickness around $739 \mathrm{~nm}$ while (VKV-cyclo/VKV- $\left.\mathrm{N}_{3}\right)_{4}$ will exhibit an estimated thickness of approximately $636 \mathrm{~nm}$. Interestingly, after 16 bilayers we will observe a decrease of the rate of the thickness growth. Therefore, we assume that after a certain number of layers the film growth achieved a plateau. Comparing the proposed modified ELR-based films with other ELR-based systems already reported in literature based on electrostatic interactions [26], we believe that covalent interactions allow the deposition of higher amounts of polymer and, thus, the construction of thicker films with less number of bilayers. Moreover, comparing our clickable based multilayer system with other covalent-driven 


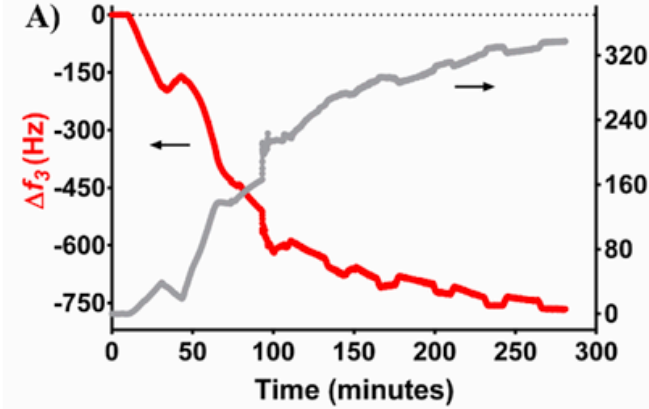

C)

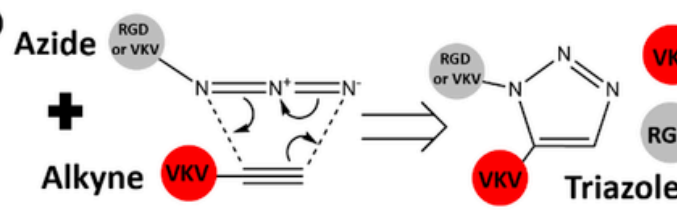

D)

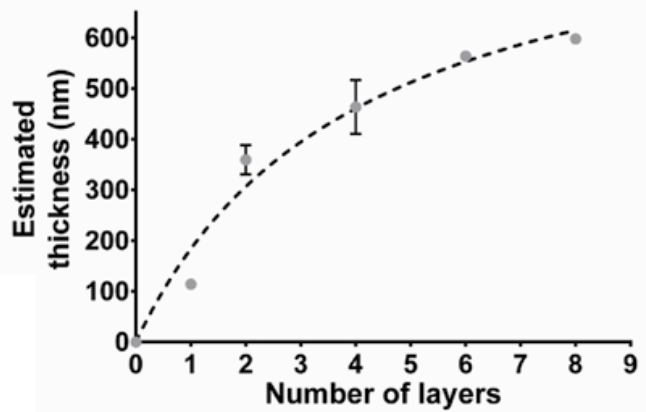

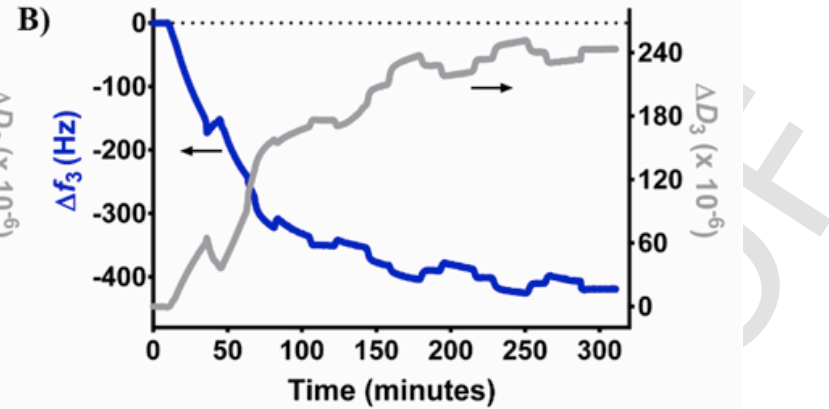

MESLLP VG VPGVG [VPGKG(VPGVG) $]_{23}$ VPGKG VPGVG VPGVG VPGVG VPGV

MGSSHHHHHHSSGLVPRGSHMESLLP [(VPGIG) $\left.)_{2}(\mathrm{VPGKG})(\mathrm{VPGIG})_{2}\right]_{2}$ AVTGRGDSPASS $\left[(\mathrm{VPGIG})_{2}(\mathrm{VPGKG})(\mathrm{VPGIG})_{2}\right]_{2}$

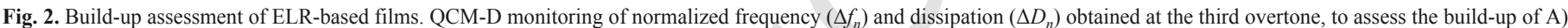

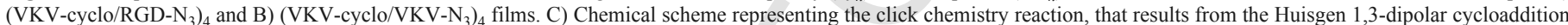

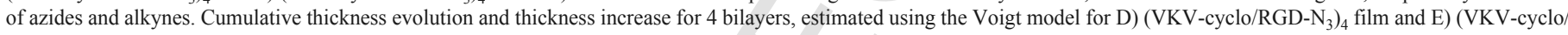
$\left.\mathrm{VKV}-\mathrm{N}_{3}\right)_{4}$ films. The cumulative thicknesses follow non-linear growth model.

systems $[21,47]$ we are able to produce thicker films, which means that we can control more precisely the final thickness of the system.

\subsection{Elastin-based films production and characterization}

The same procedure as the one described for QCM-D build-up was implemented over cleaned and activated glass coverslips, at RT. The solutions were maintained at $4{ }^{\circ} \mathrm{C}$, until use, as well as during the incubation steps, to avoid the collapse process of ELRs in solution.

The fluorescence images of the 4 bilayers coatings are presented in Fig. 3A. Following the intensity of the fluorescence of Acetylene Fluor 488 (absorption at $501 \mathrm{~nm}$ and emission at $525 \mathrm{~nm}$ ), it could be observed quite uniform distribution of the intensity on (VKV-cyclo/ RGD-N $)_{4}$ films, in red, and $(\mathrm{VKV} \text {-cyclo/VKV-N })_{4}$ films, in blue. The surfaces of the glass coverslips were visibly covered by a thin film. This observation was shared for both $\left(\mathrm{VKV} \text {-cyclo/RDG- } \mathrm{N}_{3}\right)_{4}$ and $(\mathrm{VKV} \text {-cyclo/VKV-N })_{4}$ coatings. This result is in accordance with the observations retained from QCM-D monitoring, where 4 bilayer systems were constructed with success.

Additionally, the topography of 1 bilayer and 4 bilayers of (VKV-cyclo/RDG-N ${ }_{3}$ ) and $\left(\mathrm{VKV}\right.$-cyclo/VKV-N ${ }_{3}$ ) systems processed and maintained at RT were evaluated under AFM observation-see Fig. $3 \mathrm{~B}$. As we worked at a temperature close to LCST nano-sized polymer agglomerates can be clearly observed on the surface of the coatings, resulting from the collapse of adjacent ELRs chains. For both 1
E)

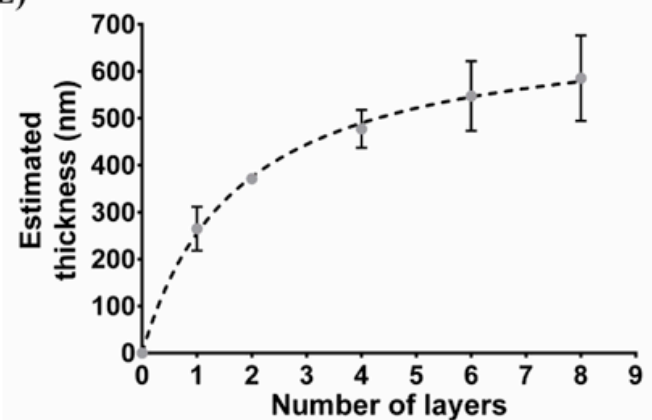

bilayer systems, a high density of irregularities was perceived and the films presented higher values of roughness $\left(\mathrm{R}_{a}=22 \pm 5.0 \mathrm{~nm}\right.$ for (VKV-cyclo/RDG- $\mathrm{N}_{3}$ ) and $\mathrm{R}_{a}=22 \pm 9.8 \mathrm{~nm}$ for (VKV-cyclo/ VKV $\left.-\mathrm{N}_{3}\right)$ ) when compared with other related reported systems $[45,48,49]$. No significant differences were detected between the roughness of $(\mathrm{VKV} \text {-cyclo/RDG-N })_{3}$ and $(\mathrm{VKV} \text {-cyclo/VKV-N })_{4}$ films. Moreover, the roughness significantly increased with the increasing number of bilayers with $\mathrm{R}_{a}=72 \pm 55.5 \mathrm{~nm}$ for (VKV-cyclo/ RDG- $\left.\mathrm{N}_{3}\right)_{4}$, which could be a result of an increasing of mass adsorbed on the surface of the glass coverslips. This observation was already reported in literature for other LbL systems [50,51]. Nonetheless, this increase of roughness was smaller for $(\mathrm{VKV} \text {-cyclo/VKV-N })_{4}$, with $\mathrm{R}_{\mathrm{a}}=25.4 \pm 14.0 \mathrm{~nm}$. QCM-D results are in accordance with AFM observation since rough surfaces induce larger hydrodynamic thicknesses [50], as the ones estimated based on the Voigt Model.

\subsection{Stimuli-responsiveness properties}

We investigated the ability of the $\left(\mathrm{VKV} \text {-cyclo/RDG- } \mathrm{N}_{3}\right)_{4}$ and (VKV-cyclo/VKV-N ${ }_{3}$ ) coatings to respond to changes in the medium such as $\mathrm{pH}$ and temperature, which are parameters that influence the adsorption of proteins at solid/liquid interface [52], among other physicochemical processes. This ability has been gaining importance and different works have been reported towards tissue engineering [53], sensors [54] and drug release systems [55]. 
A)
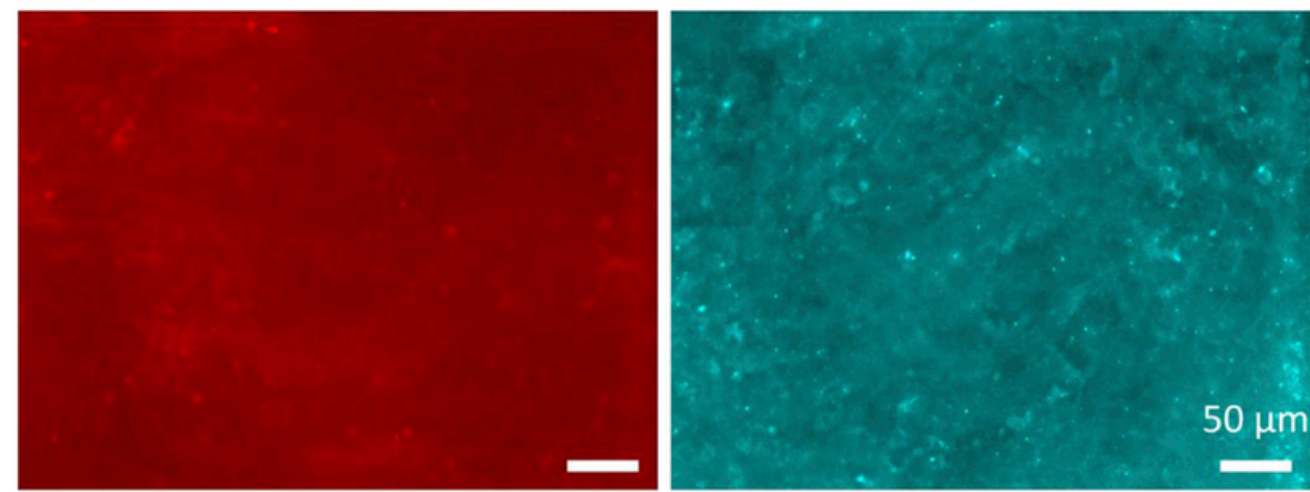

$(\mathrm{VKV} \text {-cyclo/RGD-N })_{4}$

$(\mathrm{VKV} \text {-cyclo/VKV-N })_{4}$

B)
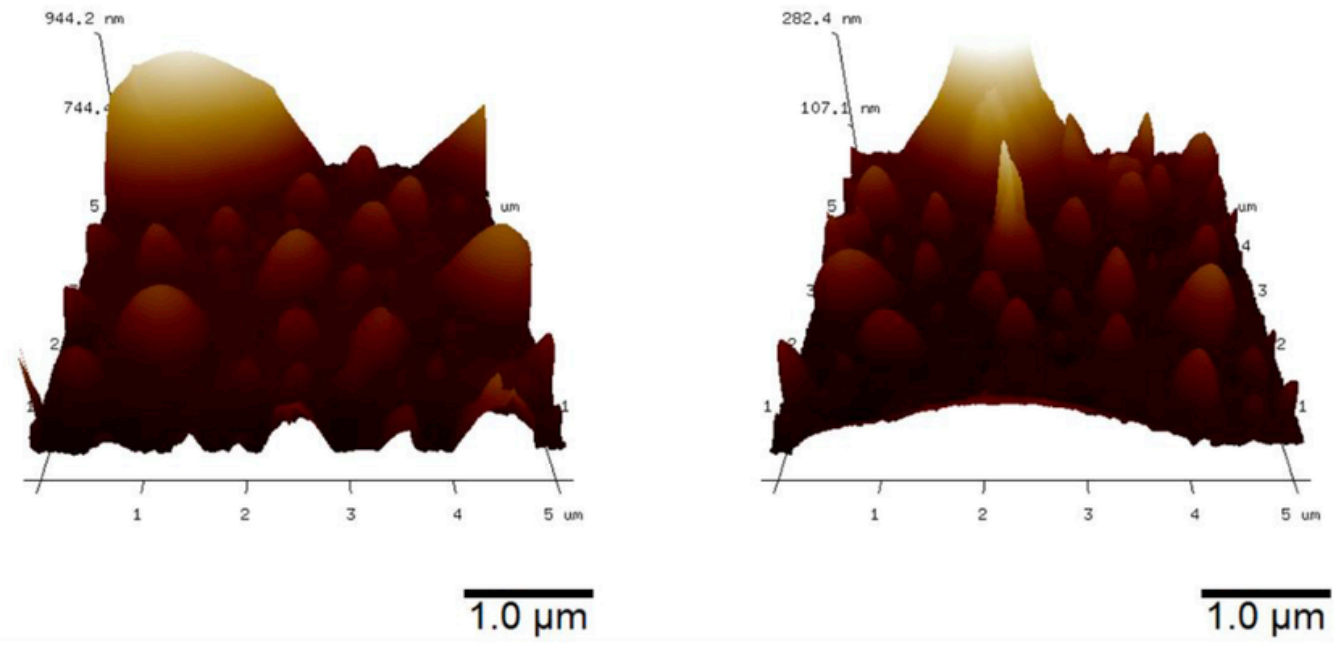

$\left(\mathrm{VKV}-\mathrm{cyclo} / \mathrm{RGD}-\mathrm{N}_{3}\right)_{1}$
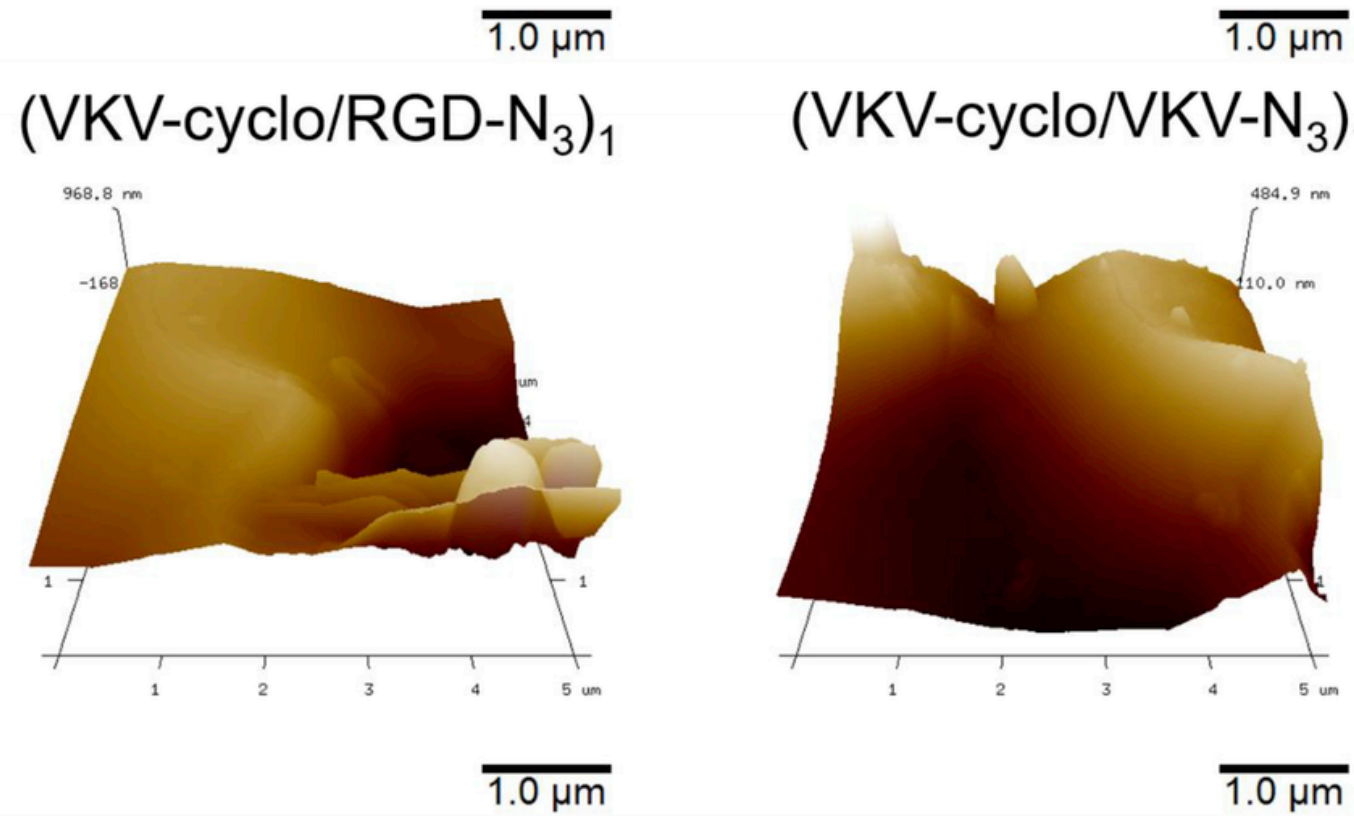

$\left(\mathrm{VKV}-\mathrm{cyclo} / \mathrm{VKV}-\mathrm{N}_{3}\right)_{1}$

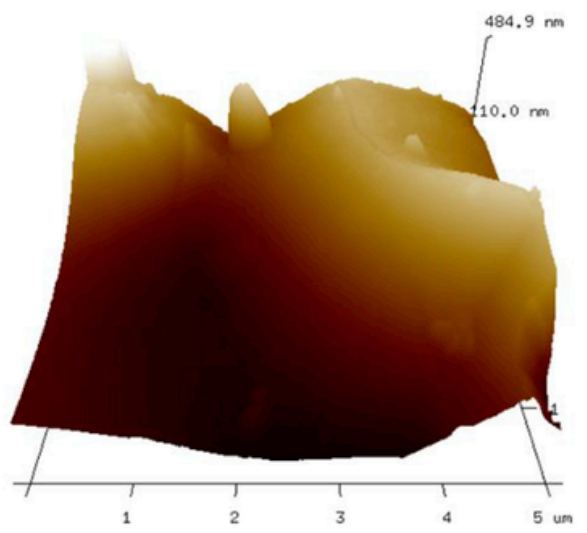

$\left(\mathrm{VKV} \text {-cyclo/RGD-N }{ }_{3}\right)_{4}$

$\left(\mathrm{VKV}-\mathrm{cyclo} / \mathrm{VKV}-\mathrm{N}_{3}\right)_{4}$

Fig. 3. A) Fluorescence images of (VKV-N $3 /$ RGD-cyclo) $)_{4}$ and $\left(\mathrm{VKV}-\mathrm{N}_{3} / \mathrm{VKV} \text {-cyclo) }\right)_{4}$ coatings (azide-modified ELRS were labelled with Acetylene Fluor 488 , before LbL construction). The coatings were produced and dried at RT. The scale bar is representative for both images. B) AFM images of (VKV-N $\left.\mathrm{N}_{3} / \mathrm{RGD}^{-c y c l o}\right)_{1}$ and $\left(\mathrm{VKV}-\mathrm{N}_{3} / \mathrm{VKV}-\mathrm{cyclo}\right)_{1}$ and $\left(\mathrm{VKV}-\mathrm{N}_{3} / \mathrm{RGD}^{-} \text {-yclo }\right)_{4}$ and $\left(\mathrm{VKV}-\mathrm{N}_{3} / \mathrm{VKV} \text {-cyclo }\right)_{4}$ coatings. 
After drying, (VKV-cyclo/RDG-N $)_{4}$ and $(\mathrm{VKV} \text {-cyclo/VKV-N })_{3}$ surfaces were maintained at RT. SEM images were used to evaluate the morphology of the coatings-see Fig. 4. At RT, both coatings seem to be well distributed over the glass coverslips, even though with some small precipitated polymer. This result was already expected since we constructed and maintained the coatings at a temperature close to LCST. Other conditions were evaluated to study the response to temperature. For that, after constructing the films, at RT, onto glass coverslips the drying process was made at different temperatures: $4{ }^{\circ} \mathrm{C}$, RT and $37^{\circ} \mathrm{C}$. Some morphological differences are noticed on SEM images; with the significant increase of the temperature above LCST $\left(37^{\circ} \mathrm{C}\right)$ the morphology of $(\mathrm{VKV} \text {-cyclo/RDG-N })_{4}$ and $(\mathrm{VKV}$-cyclo/ $\left.\mathrm{VKV}-\mathrm{N}_{3}\right)_{4}$ films seem less homogeneous with small aggregated polymer precipitates adhered all over the glass surfaces and even some salt precipitation. Working at $4{ }^{\circ} \mathrm{C}$, below LCST, the morphology of the coatings seems to be uniformly distributed on the surfaces, with less rough topography. These morphological changes are related with the thermosensitive behavior of these polymers, which are dependent of their LCST [7,56], even after the film construction.

WCA measurements assess the effect of temperature and $\mathrm{pH}$ on the wettability of the $(\mathrm{VKV} \text {-cyclo/RDG-N })_{3}$ and $(\mathrm{VKV} \text {-cyclo/VKV-N })_{4}$ coatings. To investigate the temperature effect, the WCA measurements were made under controlled temperature and humidity - see Fig. 5A. At RT, (VKV-cyclo/RDG-N $\left.{ }_{3}\right)_{4}$ and $(\mathrm{VKV}-\text { cyclo/VKV-N })_{4}$ coatings presented WCA values of $94 \pm 8.1^{\circ}$ and $84 \pm 7.3^{\circ}$, respectively. These values are closed to the threshold of hydrophobicity $\left(\mathrm{WCA}>90^{\circ}\right)$. Therefore, we assumed that at RT the coatings have a moderate hydrophobic nature. The WCA of the uncoated glass slides is $59 \pm 1.6^{\circ}$. The effectiveness of the coatings was also confirmed by the differences in the WCA, comparing the pre- and the post-coating values. By varying the temperature from $37{ }^{\circ} \mathrm{C}$ to $4{ }^{\circ} \mathrm{C}$ in repeating cycles, we observed switchable values of WCA. Higher values of WCA were observed when the samples were incubated at $37^{\circ} \mathrm{C}$ (above the LCST); on the contrary, at temperature below LCST $\left(4^{\circ} \mathrm{C}\right)$ the WCA values were consistently lower. For instance, in the last cycle, the WCA at $37^{\circ} \mathrm{C}$ was $110 \pm 11.5^{\circ}$ for $\left(V K V\right.$-cyclo/RDG- $\left.\mathrm{N}_{3}\right)$ films and $110 \pm 12.5^{\circ}$ for $(\mathrm{VKV} \text {-cyclo/VKV-N })_{4}$. On the other hand, for the last cycle at $4{ }^{\circ} \mathrm{C}$ the WCA value was about $59 \pm 14.1^{\circ}$ for (VKV-cyclo/RDG- $\left.\mathrm{N}_{3}\right)_{4}$ films and $69 \pm 6.7^{\circ}$ for $\left.(\mathrm{VKV} \text {-cyclo/VKV-N })_{3}\right)_{4}$. The images acquired for the calculation of WCA during these temperature cycles are also depicted - see Fig. 5B. These observations can be a result of temperature and individual properties of the modified ELRs. The three ELRs employed in the films construction showed similar physicochemical characteristics; the competition between intra and intermolecular hydrogen bonding above and below the LCST confers a thermosensitive nature to each individual ELR. When temperature was above LCST, the conformation of the ELRs chains started to collapse excluding water and adopting a type-II $\beta$-turns stabilized by intramolecular electrostatics forces between different groups within the polymer chains. Two consequences could derive from this phenomenon: the interaction between hydrophilic carboxyl and amine groups and water molecules became more difficult and rounded polymer nano-precipitates were observed all over the surface. The presence of the nano-precipitates impelled the increase of the roughness of the coatings. Based on Cassie and Baxter model [57], which describes the entrapment of air-pockets between the grooves and the liquid droplet, we could extrapolate what happens to WCA with the presence of rougher surfaces. With the polymer collapse process, ELRs chains fold and the coatings became rougher; when a droplet is dispensed in a rough surface, the volume of water infiltrated in the nanostructure decrease and the volume of water on the surface increase; this phenomenon resulted in the increase of WCA values. While working at temperatures below LCST, the hydrophilic groups could easily interact with the water molecules, forming water clathrates surrounding the backbone of the ELR. Besides that, as already observed, at $4{ }^{\circ} \mathrm{C}$ the surfaces became smoother, with the absence of collapse structures on their surface morphology. The combination of these two effects results on more hydrophilic films. Moreover, playing with temperature below and above LCST could also promote the reconfiguration of the hydrophobic domains: above LCST the hydrophobic chains could be exposed to the outside of the films, decreasing the surface affinity to water. The results exposed a strong dependency on temperature indicating the ability to produce smart coatings with switchable wettability using these recombinant materials [5]. Both (VKV-cyclo/RDG- $\left.\mathrm{N}_{3}\right)_{4}$ and (VKV-cyclo/ $\left.\mathrm{VKV}-\mathrm{N}_{3}\right)_{4}$ coatings presented an apparent WCA switchability upon temperature fluctuations. ELRs are well-known as protein-based polymers which present a phase transition in solution above a critical temperature [58]. Responsive polyelectrolyte coatings including ELRs were reported before [7]. However, contrasting with these results, we obtained elastin-based coatings that present a hydrophobic behavior above LCST and a hydrophilic behavior below LCST. Our thermo-responsive system can be interesting for tissue engineering field where, for example, modified surfaces with PNIPAAm have been

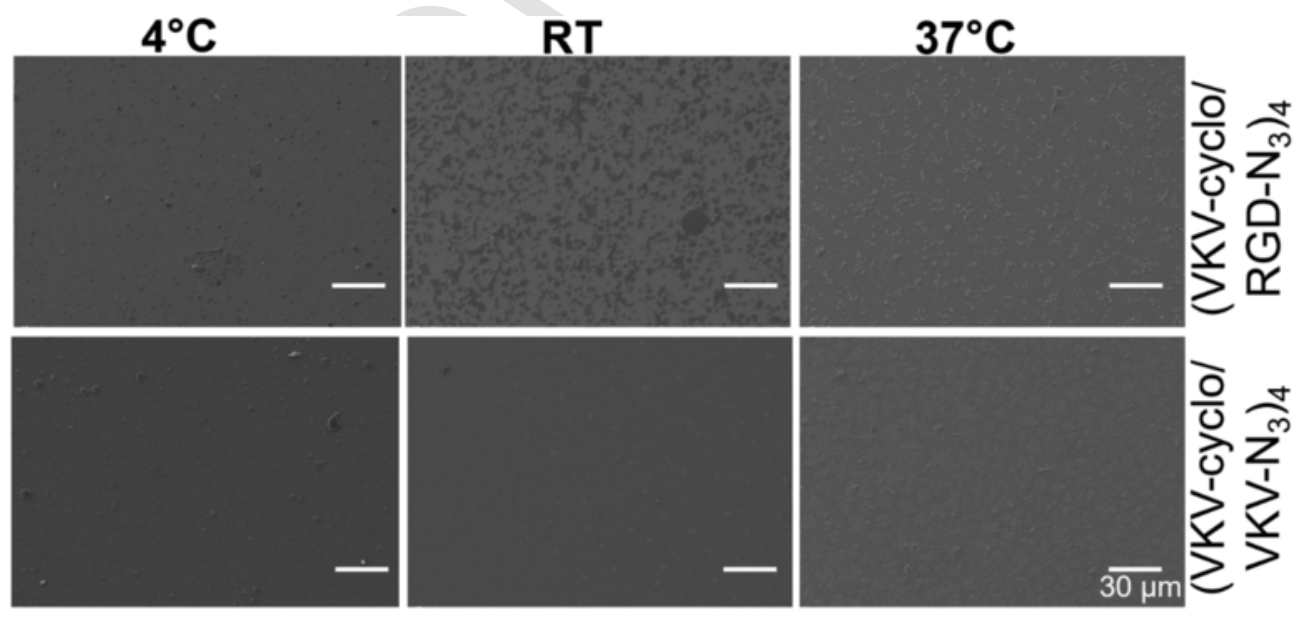

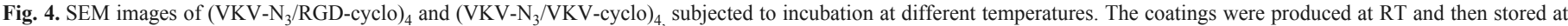
$4{ }^{\circ} \mathrm{C}$, RT and $37^{\circ} \mathrm{C}$, overnight. The scale bar is representative for all images. 
A)

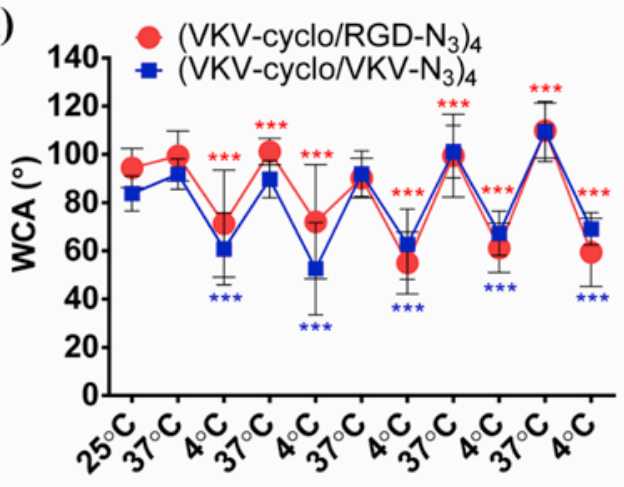

C)

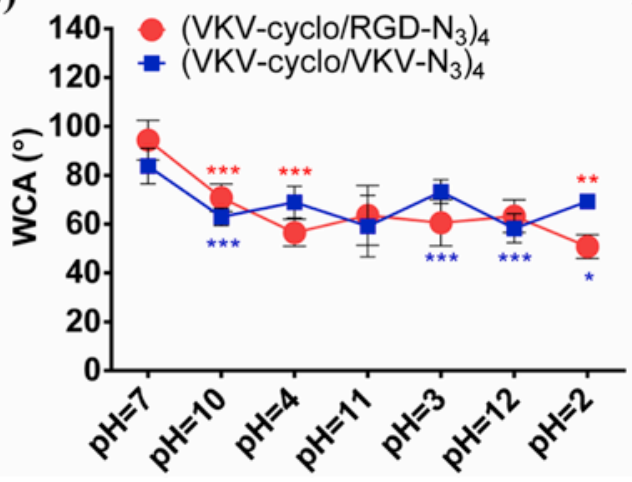

B)

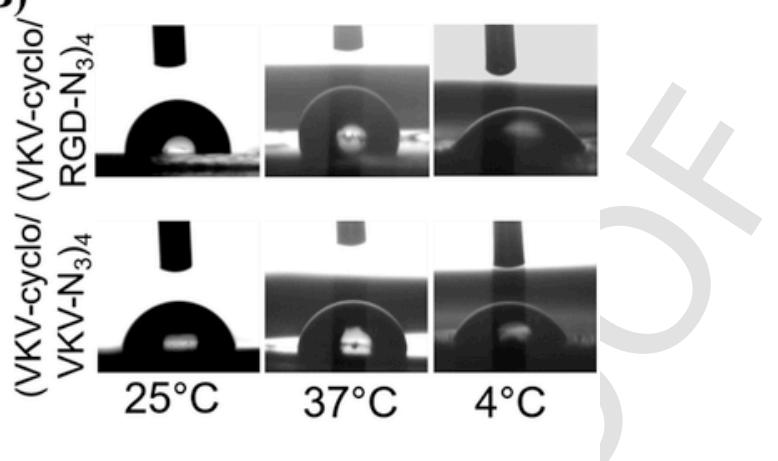

D)

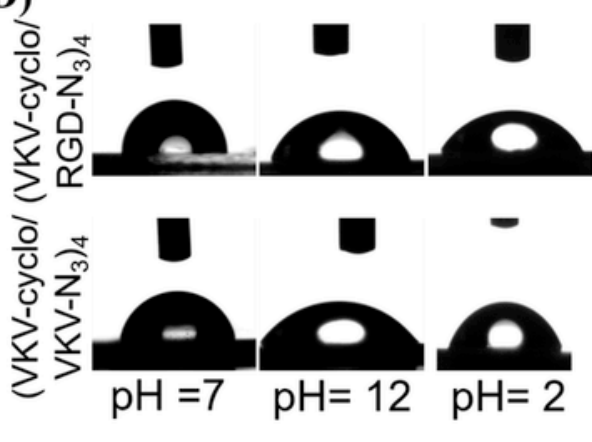

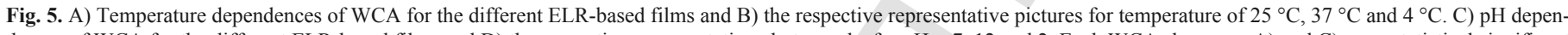

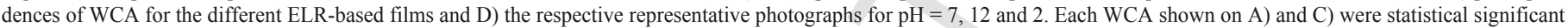
from the previous one, for $\mathrm{p}<0.05(*), \mathrm{p}<0.01\left({ }^{*}\right)$ and $\mathrm{p}<0.001$.

broadly reported $[53,59]$ to produce cell sheets based on similar hydrophilic-to-hydrophobic reversible effect of temperature on wettability.

To investigate the effect of the $\mathrm{pH}$, ELRs-coated surfaces were immersed in sodium acetate solutions at different extreme acidic and alkaline $\mathrm{pH}$ values, fixing temperature the temperature at RT. WCA measurements - see Fig. 5C - were performed after incubations of at least $1 \mathrm{~h}$ and a small step for drying of $30 \mathrm{~s}$. The representative images of the WCA for the different conditions is shown in Fig. 5D. At $\mathrm{pH} 7,(\mathrm{VKV} \text {-cyclo/RDG-N })_{4}$ presented a WCA value of $94 \pm 8.1^{\circ}$ and $(\mathrm{VKV} \text {-cyclo/VKV-N })_{3}$ coatings presented a WCA of $84 \pm 7.3^{\circ}$. Some deviations from the initial WCA were obtained; for (VKV-cyclo/RDG- $\left.\mathrm{N}_{3}\right)_{4}$ and $\left(\mathrm{VKV} \text {-cyclo/VKV-N }{ }_{3}\right)_{4}$ films, both acidic and alkaline pathways meant a more hydrophilic behavior. This could be understood by the isoelectric point; as already suggested by the $\zeta$-potential measurements; close to $\mathrm{pH} 7$, the electrostatic charges were almost neutralized. For $\left(\mathrm{VKV} \text {-cyclo/RGD-N }{ }_{3}\right)_{4}$ coatings on acidic or alkaline environments no significant differences were found in the WCA presented at acidic or alkaline routes, but a slightly increase on hydrophilicity was detected at acidic $\mathrm{pH}$. Indeed, at $\mathrm{pH}$ 2, (VKV-cyclo/RDG- $\left.\mathrm{N}_{3}\right)_{4}$ films exhibited a significantly more hydrophilic behavior. At extreme acidic $\mathrm{pH}$, amine groups were protonated and positive electrostatic forces came to be dominant: the ELRs chains expanded and the films became more hydrophilic. Despite that, for (VKV-cyclo/ $\left.\mathrm{VKV}-\mathrm{N}_{3}\right)_{4}$ coatings on acidic or alkaline environments, slightly higher WCA values were obtained at acidic $\mathrm{pH}$ values. This could be related to the balance between charged amine and acids being different from (VKV-cyclo/RDG-N $)_{4}$ films; probably, for $\left(\mathrm{VKV} \text {-cyclo/VKV-N }{ }_{3}\right)_{4}$ there was a higher content of charged acid groups at lower $\mathrm{pH}$.
Overall, results can be explained by the balance between hydrophobic interactions and charged repulsion $[60,61]$, and the respective competition between protonation and deprotonation at alkaline and acidic $\mathrm{pH}$ value. When environment conditions like $\mathrm{pH}$ change, the ELR-based films, which contain ionizable amine and acid groups, are capable of accepting or donating protons. Therefore, altering the $\mathrm{pH}$ can lead to changes on the degree of ionization and, subsequently, on the hydrodynamic volume of the ELRs chains $[62,63]$. In literature, different wettable behaviors of ELRs-modified surfaces can be found $[7,26,64]$. This variability is linked with the ability to introduce different genetically modified sequences, charges and molecular weight, that can alter the folding behavior at the surfaces [65].

To a better understanding of the $\mathrm{pH}$ effect on the stability of the systems immediately after the films construction, we also performed QCM-D monitoring studies. After the construction of both $\left(\mathrm{VKV} \text {-cyclo/RDG- } \mathrm{N}_{3}\right)_{4}$ and $(\mathrm{VKV} \text {-cyclo/VKV-N })_{4}$ systems, the resulting multilayers were flushed with a cyclic cascade of acidic and alkaline sodium acetate solutions, separately. QCM-D results show the build-up of four bilayers and their response to changes in $\mathrm{pH}$ in terms of $\Delta f$ and $\Delta D$ - see Fig. 6. For all cases, we took as reference the initial working $\mathrm{pH}$ 7. QCM-D data showing $\left(\mathrm{VKV} \text {-cyclo/RDG- } \mathrm{N}_{3}\right)_{4}$ and $(\mathrm{VKV} \text {-cyclo/VKV-N })_{4}$ multilayers flushed with cyclic alkaline cascade of solutions is presented in Fig. 6A and $\mathrm{B}$, respectively. For both cases, a decrease of $\Delta f_{3}$ upon flushing the film with a solution at $\mathrm{pH} 10$ was observed; the decrease in $\Delta f_{3}$ was reversible when the $\mathrm{pH}$ returned to 7 . Naturally, $\Delta D_{3}$ increased and $\Delta f_{3}$ decreased when the coating was flushed with the alkaline solutions. When (VKV-cyclo/RGD-N $)_{3}$ multilayers were flushed with $\mathrm{pH} 11$ and $\mathrm{pH} 12, \Delta f_{3}$ decreased with partially reversibility when $\mathrm{pH}$ returned to 7 . On the other hand, when $(\mathrm{VKV} \text {-cyclo/VKV-N })_{4}$ multilayers were flushed 

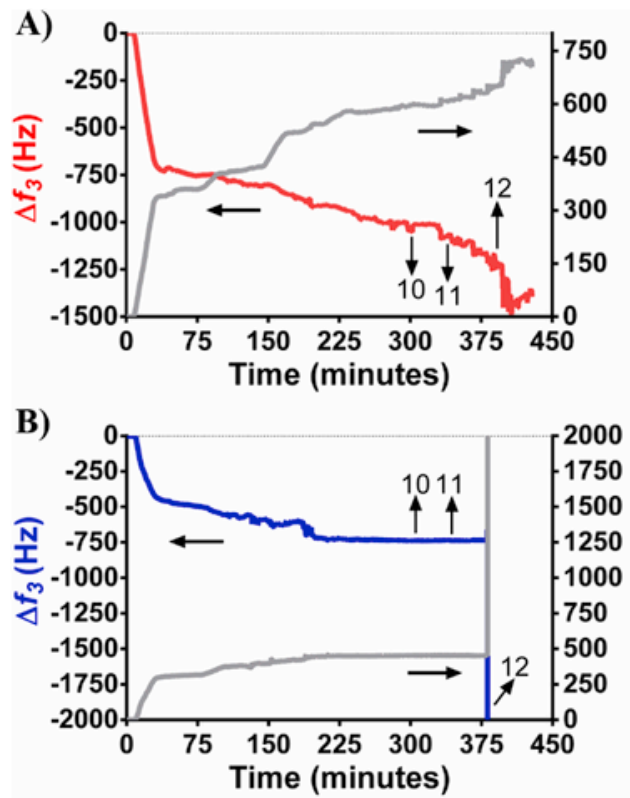
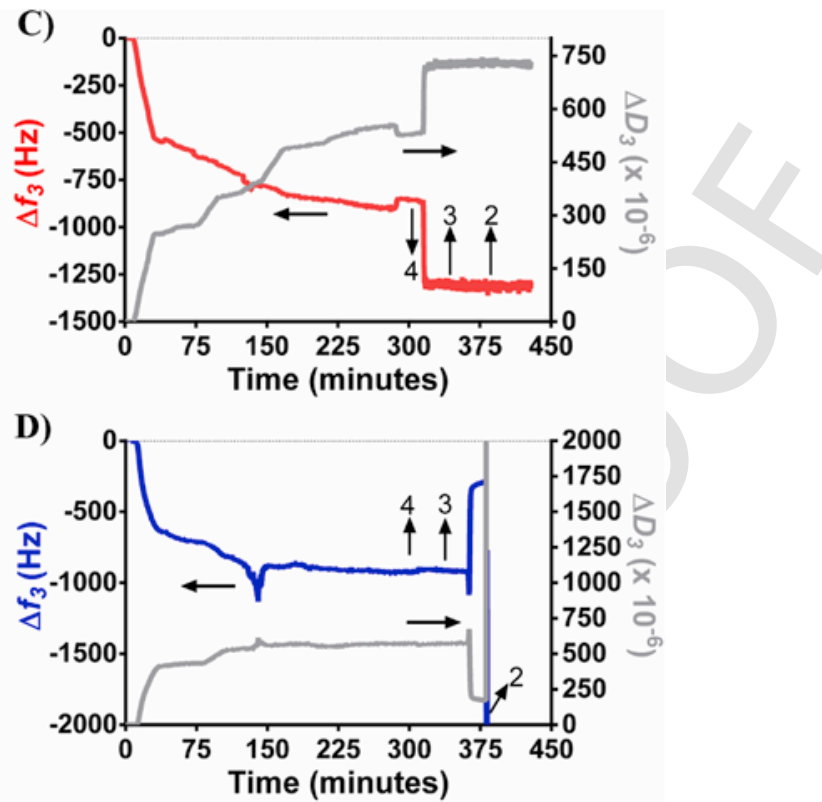

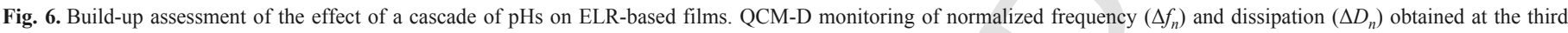

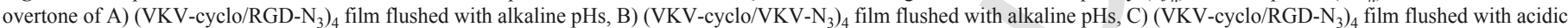
$\mathrm{pHs}$ and $\mathrm{D})(\mathrm{VKV} \text {-cyclo/VKV-N })_{4}$ film flushed with acidic $\mathrm{pHs}$.

with the solution with $\mathrm{pH} 11$ and $\mathrm{pH} 12$, the $\Delta f_{3}$ abruptly decreased with no reversibility. The same happened to $\Delta D_{3}$, which showed a great increase. Therefore, at the $\mathrm{pH} 11$ and 12, the changes in $\Delta f_{3}$ and $\Delta D_{3}$ seemed to be irreversible and could indicate that (VKV-cyclo/ VKV-N $)_{4}$ multilayers started to loose structural integrity [66].

Fig. 6C shows the QCM-D data of the $(\mathrm{VKV}-\text {-yclo/RDG-N })_{4}$ multilayers when flushed with a cyclic acidic cascade of solutions. It can be observed an abrupt decrease of $\Delta f_{3}$ when the film is flushed with solutions at $\mathrm{pH} 4$; the decrease in $\Delta f_{3}$ was irreversible when the $\mathrm{pH}$ returned to 7. At $\mathrm{pH} 3$ and $\mathrm{pH}$, there was no changes on $\Delta f_{3}$. Fig. 6D presents the QCM-D results for $(\mathrm{VKV} \text {-cyclo/VKV-N })_{4}$ multilayers when flushed with an acidic cascade of solutions. For solutions with pHs 4 and 3, the behavior of the film was similar to the one obtained for $\left(\mathrm{VKV} \text {-cyclo/RDG- } \mathrm{N}_{3}\right)_{4}$ multilayers at $\mathrm{pH} 4$. Notwithstanding, when $(\mathrm{VKV} \text {-cyclo/VKV-N })_{3}$ films were flushed with the solution at $\mathrm{pH} 2$, the decrease on the $\Delta f_{3}$ was very abrupt and higher than the others. The same happens with $\Delta D_{3}$, which exhibited a sudden increase. At this extreme acidic $\mathrm{pH}$, the changes in $\Delta f_{3}$ and $\Delta D_{3}$ seemed to be irreversible and could indicate some loss of multilayer's structural integrity. The stability and integrity of these smart coatings seemed to be maintained in a wide-range of $\mathrm{pH}$ values, being $(\mathrm{VKV} \text {-cyclo/VKV-N })_{4}$ films more susceptible at extreme $\mathrm{pH}$ (2 and 12).

Overall, properties like morphology, topography, wettability and degradability of the produced ELR-based films can be modulated through different stimuli, including temperature and $\mathrm{pH}$.

\subsection{In vitro cellular response}

ELR-coated films were cultured with $\mathrm{C} 2 \mathrm{C} 12$ cells, in order to evaluate their biomedical and tissue engineering potential. Adhesion, viability and proliferation are important parameters that depend on the interaction between material and cells [67-69]; MTS assay was used to determine the metabolic activity of $\mathrm{C} 2 \mathrm{C} 12$ adhered on the samples - see Fig. 7A. After 2 days of culture some differences started to be noticed, with $\mathrm{C} 2 \mathrm{C} 12$ cultured on $\left(\mathrm{VKV} \text {-cyclo/RDG- }{ }_{3}\right)_{4}$ films presenting significantly higher values of absorbance and, thus, higher metabolic activity. This trend was maintained and even amplified after 5 days of culture. The total amount of dsDNA on the samples was also investigated-see Fig. 7B. In the first day of culture significant differences were found between the $\left(\mathrm{VKV} \text {-cyclo/RDG- } \mathrm{N}_{3}\right)_{4}$ and $(\mathrm{VKV} \text {-cyclo/VKV-N })_{3}$ coatings, with significant higher $\mathrm{C} 2 \mathrm{C} 12$ density above the surfaces coated with $(\mathrm{VKV} \text {-cyclo/RDG-N })_{4}$ films. This result was also observed after 2 and 5 days of culture, being in accordance with the results obtained for metabolic activity. As expected, the presence of the RGD motif seemed to influence positively the cellular performance, including adhesion and proliferation, on the ELRs-coated film [26,33,70]. For instance, Picart, C. et al. [70] previously suggested the functionalization of polyelectrolyte multilayer films with RGD motifs in order to enhance primary human osteoblasts adhesion. We also investigated the morphology of $\mathrm{C} 2 \mathrm{C} 12$, analyzing the F-actin expression of cells adhered to the $(\mathrm{VKV} \text {-cyclo/RGD-N })_{4}$ and $\left(\mathrm{VKV} \text {-cyclo/VKV-N }{ }_{3}\right)_{4}$ coatings (see Fig. 7C). Some differences were observed on $\mathrm{C} 2 \mathrm{C} 12$ morphology and density as a function of culturing time. As observed in Fig. $7 \mathrm{C}$, cell density on (VKV-cyclo/RGD-N $)_{4}$ films increased with the time of culture; these results match the DNA quantification and MTS results. In the first day of culture, adhered myoblasts already acquired the star-like shape, which is characteristic of $\mathrm{C} 2 \mathrm{C} 12$ cells [36]. This phenotype could be observed more clearly on cells adhered to (VKV-cyclo/RGD-N $)_{4}$ surfaces. At 2 days of culture, myoblasts continued to proliferate and, naturally, started to fuse one with each other, creating a kind of cellular network [71]. This phenomenon was observed for both $(\mathrm{VKV} \text {-cyclo/RGD-N })_{4}$ and $(\mathrm{VKV} \text {-cyclo/VKV-N })_{4}$ surfaces, with cells being better distributed for $(\mathrm{VKV} \text {-cyclo/RGD-N })_{4}$ coatings and more clustered in $\left.(\mathrm{VKV} \text {-cyclo/VKV-N })_{3}\right)_{4}$ surfaces. At 5 days of culture, the cells occupied the entire area, forming an organized cellular monolayer above the $(\mathrm{VKV} \text {-cyclo/RGD-N })_{3}$ surface. The cells adhered to (VKV-cyclo/VKV-N $\left.{ }_{3}\right)_{4}$ films had a similar behavior but, as the rate of proliferation was visibly slower, after 5 days of culture cell-free areas could still be found on the (VKV-cyclo/ VKV-N $)_{4}$ coatings. TCPS were used as positive control and, in fact, 

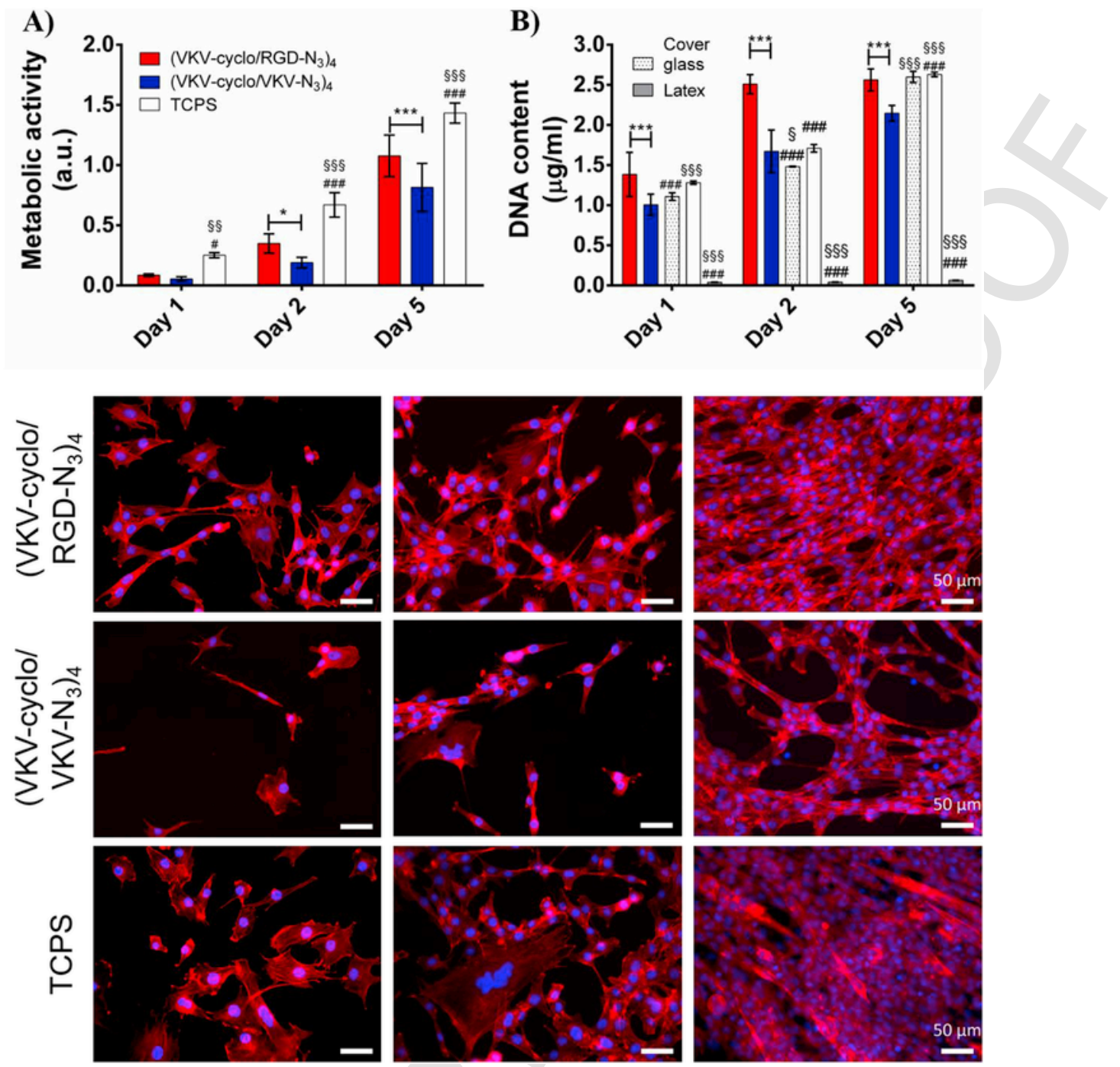

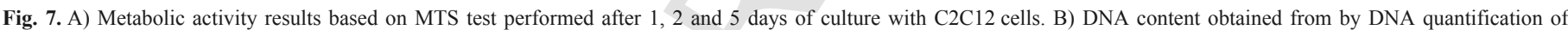

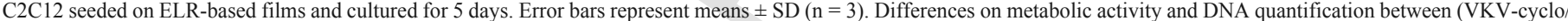

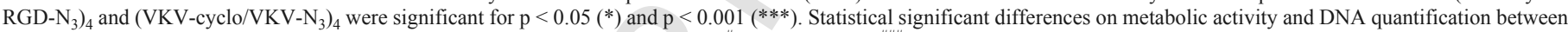

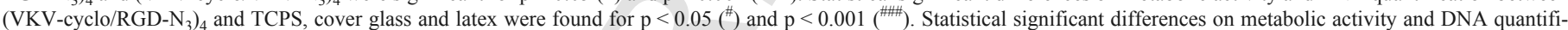

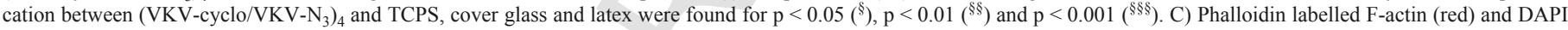

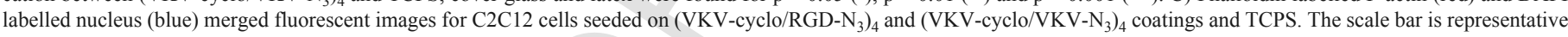
for all images. (For interpretation of the references to colour in this figure legend, the reader is referred to the web version of this article.)

cell morphology on (VKV-cyclo/RGD-N $)_{4}$ coatings was comparable to cell morphology on TCPS surfaces.

$\mathrm{C} 2 \mathrm{C} 12$ differentiation was investigated by the expression of the skeletal muscle protein Troponin T. For that, we performed an immunocytochemistry assay after culturing cells above the ELRs-coated surfaces during 5 days in differentiation medium-see Fig. 8A. Some differences were observed between Troponin-T positive cells adhered to $\left(\mathrm{VKV} \text {-cyclo/RGD- } \mathrm{N}_{3}\right)_{4}$ and $(\mathrm{VKV} \text {-cyclo/VKV-N })_{4}$ films. Visually, it is possible to observe more troponin $\mathrm{T}$ expression on the cells adhered to (VKV-cyclo/RGD-N $)_{4}$ films, with more multinucleated myotubes than on (VKV-cyclo/VKV-N $)_{4}$ films or even on TCPS. To conclude quantitatively about the myogenic differentiation on the ELR-based films, some parameters were calculated. Significant differences were observed between the fusion index of $\mathrm{C} 2 \mathrm{C} 12$ adhered to the different films. The cells seeded on (VKV-cyclo/RGD-N $)_{4}$ films presented higher fusion index percentage than the cells seeded on $(\mathrm{VKV} \text {-cyclo/VKV-N })_{4}$ - see Fig. 8B. Also, the number of my- otubes per area was significantly higher for $(\mathrm{VKV} \text {-cyclo/RGD-N })_{4}$ films - see Fig. 8C. These results together could be an evidence that myogenic differentiation of $\mathrm{C} 2 \mathrm{C} 12$ cells was stimulated by the presence of RGD motifs on material's surface. This fact is supported by some examples found in the literature [72,73], which related the presence of the RGD sequence to the promotion cellular attachment and differentiation. Different morphometric parameters were also calculated from immunofluorescence images to assess the effect of RGD on myotube formation. The average area (Fig. 8D), perimeter (Fig. 8E) and length (Fig. 8F) of myotubes were similar and very dispersed, either adhering on $(\mathrm{VKV} \text {-cyclo/RGD-N })_{4}$ or $(\mathrm{VKV} \text {-cyclo/VKV-N })_{4}$. No significant differences were found between the myotubes elongation factor of $\mathrm{C} 2 \mathrm{C} 12$ adhered to $(\mathrm{VKV} \text {-cyclo/RGD-N })_{4}$ or (VKV-cyclo/VKV-N $)_{3}-$ see Fig. 8G. Myogenic differentiation seemed to be favored by the presence of RGD motif, but the morphology of the formed myotubes was quite similar on $\left(\mathrm{VKV} \text {-cyclo/RGD- } \mathrm{N}_{3}\right)_{4}$ and $(\mathrm{VKV} \text {-cyclo/VKV-N })_{4}$ coatings. 


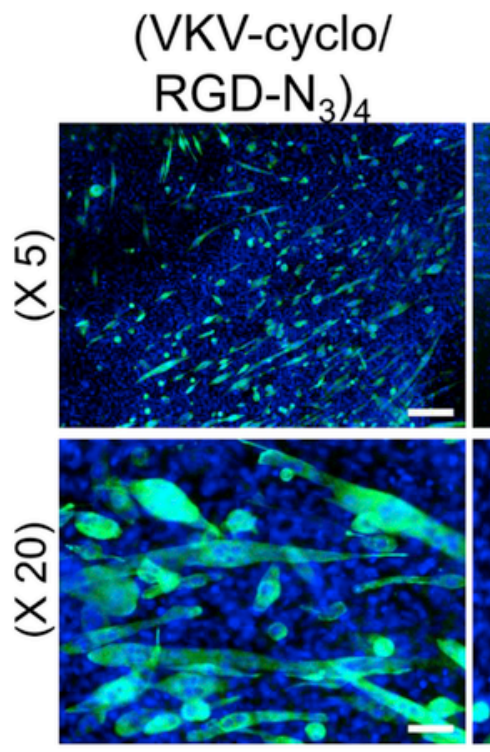

\section{(VKV-cyclo/}
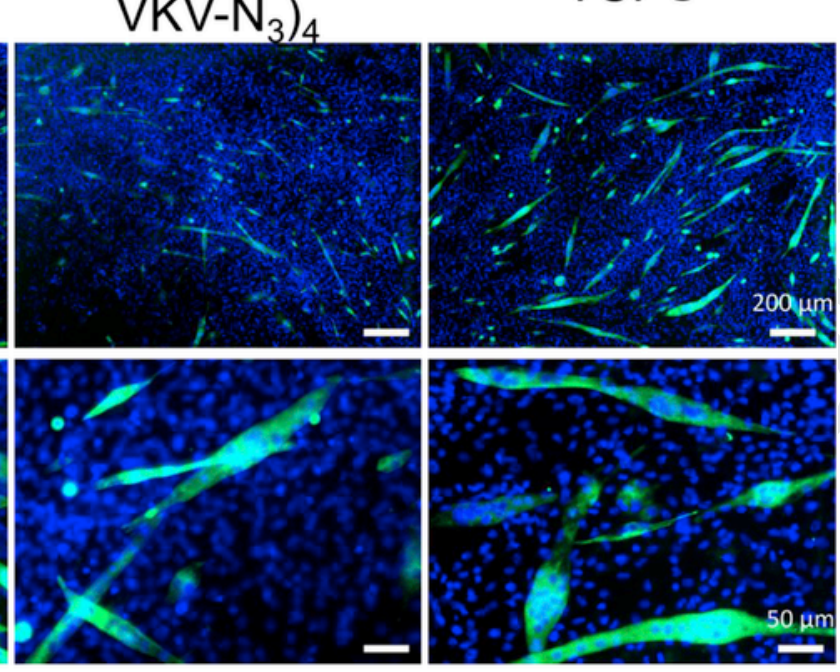

B)

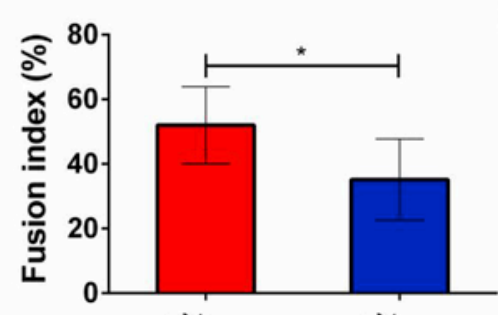

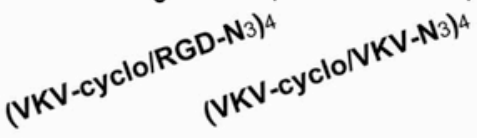

D)

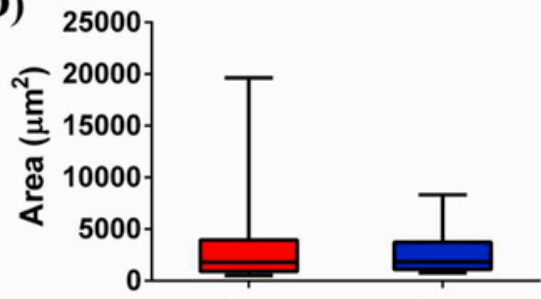

C)

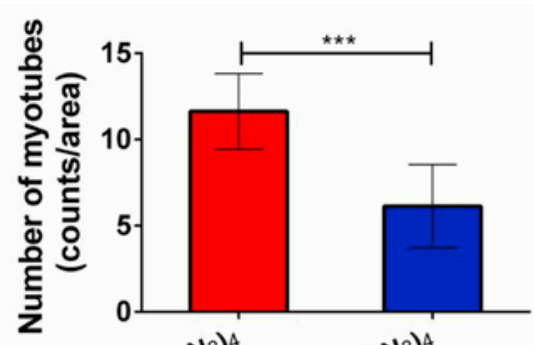

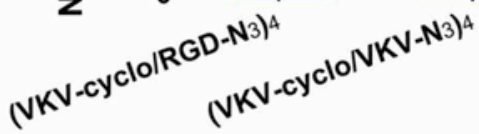

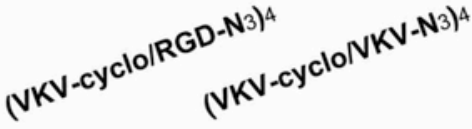

F)

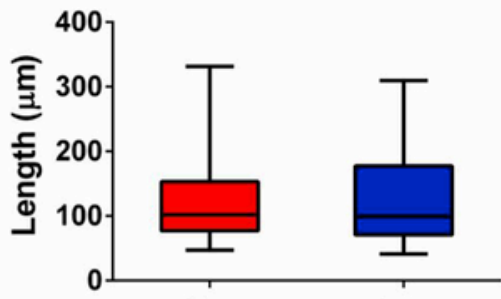

E)

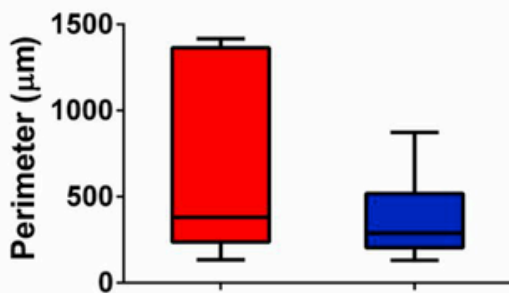

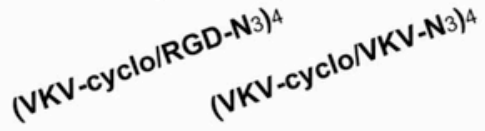

G)

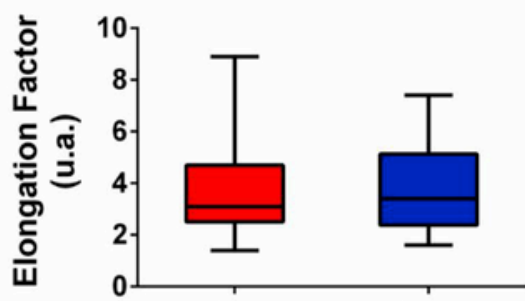

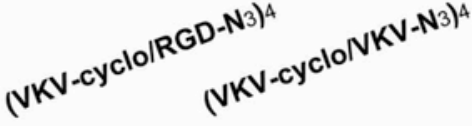

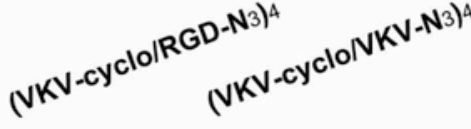

Fig. 8. A) Myogenic differentiation at day 7 of culture of the cells seeded above the (VKV-cyclo/RGD- $\left.\mathrm{N}_{3}\right)_{4},(\mathrm{VKV} \text {-cyclo/VKV-N })_{4}$ and TCPS. The images are the results of a fluorescence staining showing troponin T-positive cells (green) and cell nuclei (blue). Myogenic differentiation as determined by the B) fusion index (\%) and the C) number of my- 


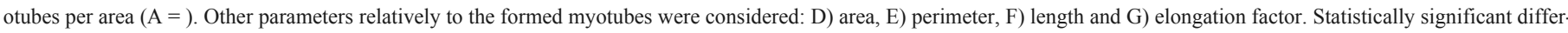

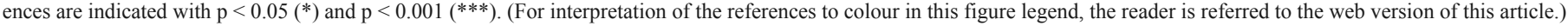

Independently of the surface energy and wettability changes of the coatings when subjected to different temperature and $\mathrm{pH}$, cell seeding was performed and maintained at $37^{\circ} \mathrm{C}$; at this temperature, the surfaces of both (VKV-cyclo/RGD-N $\left.{ }_{3}\right)_{4}$ and (VKV-cyclo/ cyclo- $\left.\mathrm{N}_{3}\right)_{4}$ coatings were moderately hydrophobic. Therefore, we hypothesize that the enhanced cell adhesion, activity and even differentiation above the $(\mathrm{VKV} \text {-cyclo/RGD-N })_{4}$ was mainly related with chemistry of the surface by the presence of the bioactive sequence RGD and in this specific case was not related with parameters like surface energy, wettability and charge.

\section{Conclusions}

We reported the development of stimuli-responsive polymer multilayer coatings, based on a click-chemistry system. We propose a simple click LbL methodology to fabricate these coatings, which consists in alternating cyclooctyne- and azide-modified ELRs, combined in a sequential multilayer mode. The build-up of the ELRs-based films was confirmed by QCM-D monitoring, following a non-linear growth. Herein, we show that both temperature and $\mathrm{pH}$ can act like stimuli to prompt independent responses by the developed ELRs-based films. Above LCST, ELRs formed folded and round structures. This phenomenon resulted in the increase of roughness of the coatings, and consequently in a more hydrophobic behavior, as compared to the ones found in the coating maintained at temperatures below LCST. Also, $\mathrm{pH}$ variations were responsible for changes in the coatings' WCA values; generally, the balance between charged amine and acid groups could determine the wetting behavior of the surfaces. The high stability of the films, conferred by the covalent bonding, was confirmed by QCM-D monitoring; in fact, the films withstood harsh conditions of $\mathrm{pH}$, and only $\left(\mathrm{VKV} \text {-cyclo/VKV-N }{ }_{3}\right)_{4}$ coatings showed integrity loss while exposed to the most extreme $\mathrm{pH}$ value. The ability to introduce specific bioactive sequences like RGD motif on the ELRs structure was relevant for this investigation and central for tissue engineering and biomedical applications. Cell proliferation was increased on (VKV-cyclo/RGD-N $)_{4}$ films, and myogenic differentiation was also favored by the presence of the RGD bioactive sequence.

Overall, we were able to produce temperature and $\mathrm{pH}$ - responsive multilayer films composed exclusively by modified elastin-like polypeptides that can be easily used to as coatings. Besides glass, we hypothesize that these films may find application on coating implants with more complex shapes and compositions, nano/microstructures, gels and membranes. These systems show a great potential to develop structures for tissue engineering purposes or as platforms to culture cells in controlled conditions.

\section{Acknowledgments}

This research has received funding from the European Union's Horizon 2020 research and innovation programme under grant agreement No.646075. Maria P. Sousa and Mariana B. Oliveira acknowledge the Portuguese Foundation for Science and Technology (FCT) the grants SFRH/BD/97606/2013 and SFRH/BPD/111354/2015.

\section{References}

[1] B. Jeong, A. Gutowska, Lessons from nature: stimuli-responsive polymers and their biomedical applications, Trends Biotechnol. 20 (2002) 305-311.

[2] M.A.C. Stuart, W.T.S. Huck, J. Genzer, M. Muller, C. Ober, M. Stamm, G.B Sukhorukov, I. Szleifer, V.V. Tsukruk, M. Urban, F. Winnik, S. Zauscher, I.
Luzinov, S. Minko, Emerging applications of stimuli-responsive polymer materials, Nat. Mater 9 (2010) 101-113.

[3] A. Nelson, Stimuli-responsive polymers: engineering interactions, Nat. Mater 7 (2008) 523-525.

[4] C. d. 1. H. Alarcon, S. Pennadam, C. Alexander, Stimuli responsive polymers for biomedical applications, Chem. Soc. Rev. 34 (2005) 276-285.

[5] J.F. Mano, Stimuli-responsive polymeric systems for biomedical applications, Adv. Eng. Mater 10 (2008) 515-527.

[6] I. Tokarev, S. Minko, Stimuli-responsive hydrogel thin films, Soft Matter 5 (2009) 511-524.

[7] R.R. Costa, C.A. Custódio, A.M. Testera, F.J. Arias, J.C. Rodríguez-Cabello, N.M. Alves, J.F. Mano, Stimuli-responsive thin coatings using elastin-like polymers for biomedical applications, Adv. Funct. Mater 19 (2009) 3210-3218.

[8] D. Wandera, S.R. Wickramasinghe, S.M. Husson, Stimuli-responsive membranes, J. Membr. Sci. 357 (2010) 6-35.

[9] X. Hu, E. McIntosh, M.G. Simon, C. Staii, S.W. Thomas, Stimuli-responsive free-standing layer-by-layer films, Adv. Mater 28 (2016) 715-721.

[10] M. Motornov, Y. Roiter, I. Tokarev, S. Minko, Stimuli-responsive nanoparticles, nanogels and capsules for integrated multifunctional intelligent systems, Prog. Polym. Sci. 35 (2010) 174-211.

[11] E. Sokolovskaya, S. Rahmani, A.C. Misra, S. Bräse, J. Lahann, Dual-stimuli-responsive microparticles, ACS Appl. Mater. Interfaces 7 (2015) 9744-9751.

[12] R.R. Costa, J.F. Mano, Polyelectrolyte multilayered assemblies in biomedical technologies, Chem. Soc. Rev. 43 (2014) 3453-3479.

[13] L. Richert, P. Lavalle, E. Payan, X.Z. Shu, G.D. Prestwich, J.-F. Stoltz, P. Schaaf, J.-C. Voegel, C. Picart, Layer by layer buildup of polysaccharide films: physical chemistry and cellular adhesion aspects, Langmuir 20 (2004) 448-458.

[14] J.F. Quinn, F. Caruso, Facile tailoring of film morphology and release properties using layer-by-layer assembly of thermoresponsive materials, Langmuir 20 (2004) 20-22.

[15] J.M. Silva, R.L. Reis, J.F. Mano, Biomimetic extracellular environment based on natural origin polyelectrolyte multilayers, Small 12 (2016) 4308-4342.

[16] J. Borges, J.F. Mano, Molecular interactions driving the layer-by-layer assembly of multilayers, Chem. Rev. 114 (2014) 8883-8942.

[17] J. Borges, J.F. Mano, Molecular interactions driving the layer-by-layer assembly of multilayers, Chem. Rev. 114 (2014) 8883-8942.

[18] J.F. Quinn, A.P.R. Johnston, G.K. Such, A.N. Zelikin, F. Caruso, Next generation, sequentially assembled ultrathin films: beyond electrostatics, Chem. Soc. Rev. 36 (2007) 707-718.

[19] D.E. Bergbreiter, K.-S. Liao, Covalent layer-by-layer assembly-an effective, forgiving way to construct functional robust ultrathin films and nanocomposites, Soft Matter 5 (2009) 23-28.

[20] J. Seo, P. Schattling, T. Lang, F. Jochum, K. Nilles, P. Theato, K. Char, Covalently bonded layer-by-layer assembly of multifunctional thin films based on activated esters, Langmuir 26 (2010) 1830-1836.

[21] G.K. Such, E. Tjipto, A. Postma, A.P.R. Johnston, F. Caruso, Ultrathin, responsive polymer click capsules, Nano Lett. 7 (2007) 1706-1710.

[22] V.V. Rostovtsev, L.G. Green, V.V. Fokin, K.B. Sharpless, A stepwise Huisgen cycloaddition process: copper(I)-catalyzed regioselective "ligation" of azides and terminal alkynes, Angew. Chem. Int. Ed. 41 (2002). 2596-+.

[23] M. Meldal, C.W. Tornøe, Cu-catalyzed Azide-Alkyne cycloaddition, Chem Rev. 108 (2008) 2952-3015.

[24] T. Crouzier, T. Boudou, C. Picart, Polysaccharide-based polyelectrolyte multilayers, Curr. Opin. Colloid Interface Sci. 15 (2010) 417-426.

[25] J.M. Silva, A.R.C. Duarte, S.G. Caridade, C. Picart, R.L. Reis, J.F. Mano, Tailored freestanding multilayered membranes based on chitosan and alginate, Biomacromolecules 15 (2014) 3817-3826.

[26] R.R. Costa, C.A. Custódio, F.J. Arias, J.C. Rodríguez-Cabello, J.F. Mano, Layer-by-Layer assembly of chitosan and recombinant biopolymers into biomimetic coatings with multiple stimuli-responsive properties, Small 7 (2011) 2640-2649.

[27] A. Matsuzawa, M. Matsusaki, M. Akashi, Effectiveness of nanometer-sized extracellular matrix layer-by-layer assembled films for a cell membrane coating protecting cells from physical stress, Langmuir 29 (2013) 7362-7368.

[28] S.M. Oliveira, V.E. Santo, M.E. Gomes, R.L. Reis, J.F. Mano, Layer-by-layer assembled cell instructive nanocoatings containing platelet lysate, Biomaterials 48 (2015) 56-65.

[29] P. He, M. Bayachou, Layer-by-Layer fabrication and characterization of DNA-wrapped single-walled carbon nanotube particles, Langmuir 21 (2005) 6086-6092.

[30] J.C. Rodríguez-Cabello, L. Martín, A. Girotti, C. García-Arévalo, F.J. Arias, M. Alonso, Emerging applications of multifunctional elastin-like recombinamers, Nanomedicine 6 (2010) 111-122.

[31] A. Girotti, A. Fernández-Colino, I.M. López, J.C. Rodríguez-Cabello, F.J. Arias, Elastin-like recombinamers: biosynthetic strategies and biotechnological applications, Biotechnol. J. 6 (2011) 1174-1186. 
[32] S.E. D'Souza, M.H. Ginsberg, E.F. Plow, Arginyl-glycyl-aspartic acid (RGD): a cell adhesion motif, Trends biochem. Sci. 16 (1991) 246-250.

[33] U. Hersel, C. Dahmen, H. Kessler, RGD modified polymers: biomaterials for stimulated cell adhesion and beyond, Biomaterials 24 (2003) 4385-4415.

[34] I. González de Torre, M. Santos, L. Quintanilla, A. Testera, M. Alonso, J.C. Rodríguez Cabello, Elastin-like recombinamer catalyst-free click gels: characterization of poroelastic and intrinsic viscoelastic properties, Acta Biomater. 10 (2014) 2495-2505.

[35] N.M. Alves, C. Picart, J.F. Mano, Self assembling and crosslinking of polyelectrolyte multilayer films of chitosan and alginate studied by QCM and IR spectroscopy, macromol, Biosci 9 (2009) 776-785.

[36] S. Burattini, P. Ferri, M. Battistelli, R. Curci, E. Luchetti, E. Falcieri, C2C12 murine myoblasts as a model of skeletal muscle development: morpho-functional characterization, Eur. J. Histochem 48 (2004) 223-233.

[37] S. Chang, S. Song, J. Lee, J. Yoon, J. Park, S. Choi, J.-K. Park, K. Choi, C. Choi, Phenotypic modulation of primary vascular smooth muscle cells by short-term culture on micropatterned substrate, PLoS One 9 (2014) e88089.

[38] M.B. Oliveira, W. Song, L. Martin, S.M. Oliveira, S.G. Caridade, M. Alonso, J.C. Rodriguez-Cabello, J.F. Mano, Development of an injectable system based on elastin-like recombinamer particles for tissue engineering applications, Soft Matter 7 (2011) 6426-6434

[39] B. Kinikoglu, J.C. Rodríguez-Cabello, O. Damour, V. Hasirci, A smart bilayer scaffold of elastin-like recombinamer and collagen for soft tissue engineering, $\mathrm{J}$ Mater. Sci. Mater. Med. 22 (2011) 1541-1554.

[40] I. Gonzalez de Torre, M. Weber, L. Quintanilla, M. Alonso, S. Jockenhoevel, J.C. Rodriguez Cabello, P. Mela, Hybrid elastin-like recombinamer-fibrin gels: physical characterization and in vitro evaluation for cardiovascular tissue engineering applications, Biomater. Sci. 4 (2016) 1361-1370.

[41] A. Girotti, J. Reguera, F.J. Arias, M. Alonso, A.M. Testera, J.C. Rodríguez-Cabello, Influence of the molecular weight on the inverse temperature transition of a model genetically engineered elastin-like $\mathrm{pH}$-responsive polymer, Macromolecules 37 (2004) 3396-3400.

[42] I. González de Torre, L. Quintanilla, G. Pinedo-Martín, M. Alonso, J.C. Rodríguez-Cabello, Nanogel formation from dilute solutions of clickable elastin-like recombinamers and its dependence on temperature: two fractal gelation modes, ACS Appl. Mater. Interfaces 6 (2014) 14509-14515.

[43] U. Glebe, B. Santos de Miranda, P. van Rijn, A. Boker, Synthetic modifications of proteins, Bio-Synth. Hybrid Mater. Bionanoparticles A Biol. Chem. Approach Towards Mater. Sci. R. Soc. Chem. (2015) 1-29.

[44] K.A. Marx, Quartz crystal Microbalance: a useful tool for studying thin polymer films and complex biomolecular systems at the Solution-Surface interface, Biomacromolecules 4 (2003) 1099-1120.

[45] G.K. Such, J.F. Quinn, A. Quinn, E. Tjipto, F. Caruso, Assembly of ultrathin polymer multilayer films by click chemistry, J. Am. Chem. Soc. 128 (2006) 9318-9319.

[46] C.R. Kinnane, K. Wark, G.K. Such, A.P.R. Johnston, F. Caruso, Peptide-functionalized, low-biofouling click multilayers for promoting cell adhesion and growth, Small 5 (2009) 444-448.

[47] T. Xiang, R. Wang, W.-F. Zhao, S.-D. Sun, C.-S. Zhao, Covalent deposition of zwitterionic polymer and citric acid by click chemistry-enabled layer-by-layer assembly for improving the blood compatibility of polysulfone membrane, Langmuir 30 (2014) 5115-5125.

[48] M. Golonka, M. Bulwan, M. Nowakowska, A.M. Testera, J.C. Rodriguez-Cabello, S. Zapotoczny, Thermoresponsive multilayer films based on ionic elastin-like recombinamers, Soft Matter 7 (2011) 9402-9409.

[49] W.J. Yang, D. Pranantyo, K.-G. Neoh, E.-T. Kang, S.L.-M. Teo, D. Rittschof, Layer-by-Layer click deposition of functional polymer coatings for combating marine biofouling, Biomacromolecules 13 (2012) 2769-2780.

[50] A.E. El haitami, J.-S. Thomann, L. Jierry, a. Parat, J.-C. Voegel, P. Schaaf, B. Senger, F. Boulmedais, B. Frisch, covalent layer-by-layer assemblies of polyelectrolytes and homobifunctional spacers, Langmuir 26 (2010) 12351-12357.

[51] C. Elosua, D. Lopez-Torres, M. Hernaez, I.R. Matias, F.J. Arregui, Comparative study of layer-by-layer deposition techniques for poly(sodium phosphate) and poly(allylamine hydrochloride), Nanoscale Res. Lett. 8 (2013) 539.
[52] W. Norde, F. MacRitchie, G. Nowicka, J. Lyklema, Protein adsorption at solid-liquid interfaces: reversibility and conformation aspects, J. Colloid Interface Sci. 112 (1986) 447-456.

[53] R.M.P. da Silva, J.F. Mano, R.L. Reis, Smart thermoresponsive coatings and surfaces for tissue engineering: switching cell-material boundaries, Trends Biotechnol. 25 (2007) 577-583.

[54] O. Parlak, M. Ashaduzzaman, S.B. Kollipara, A. Tiwari, A.P.F. Turner, Switchable bioelectrocatalysis controlled by dual stimuli-responsive polymeric interface, ACS Appl. Mater. Interfaces 7 (2015) 23837-23847.

[55] H. Vihola, A. Laukkanen, H. Tenhu, J. Hirvonen, Drug release characteristics of physically cross-linked thermosensitive poly(N-vinylcaprolactam) hydrogel particles, J. Pharm. Sci. 97 (2008) 4783-4793.

[56] A.M. Testera, A. Girotti, I.G. de Torre, L. Quintanilla, M. Santos, M. Alonso, J.C. Rodríguez-Cabello, Biocompatible elastin-like click gels: design, synthesis and characterization, J. Mater. Sci. Mater. Med. 26 (2015) 1-13.

[57] R.N. Wenzel, Resistance of solid surfaces to wetting by water, Ind. Eng. Chem. 28 (1936) 988-994.

[58] T. Kowalczyk, K. Hnatuszko-Konka, A. Gerszberg, A.K. Kononowicz, Elastin-like polypeptides as a promising family of genetically-engineered protein based polymers, World J. Microbiol. Biotechnol. 30 (2014) 2141-2152.

[59] T. Shimizu, M. Yamato, A. Kikuchi, T. Okano, Cell sheet engineering for myocardial tissue reconstruction, Biomaterials 24 (2003) 2309-2316.

[60] B. Li, V. Daggett, The molecular basis of the temperature- and $\mathrm{pH}$-induced conformational transitions in elastin-based peptides, Biopolymers 68 (2003) 121-129.

[61] J. Carlos Rodríguez-Cabello, J. Reguera, A. Girotti, M. Alonso, A.M. Testera, Developing functionality in elastin-like polymers by increasing their molecular complexity: the power of the genetic engineering approach, Prog. Polym. Sci. 30 (2005) 1119-1145.

[62] F. Xia, L. Feng, S. Wang, T. Sun, W. Song, W. Jiang, L. Jiang, Dual-responsive surfaces that switch between superhydrophilicity and superhydrophobicity, adv, Mater 18 (2006) 432-436.

[63] Q. Zhang, F. Xia, T. Sun, W. Song, T. Zhao, M. Liu, L. Jiang, Wettability switching between high hydrophilicity at low $\mathrm{pH}$ and high hydrophobicity at high $\mathrm{pH}$ on surface based on $\mathrm{pH}-$ responsive polymer, Chem. Commun. (2008) 1199-1201.

[64] E.M. Srokowski, K.A. Woodhouse, Surface and adsorption characteristics of three elastin-like polypeptide coatings with varying sequence lengths, J. Mater. Sci. Mater. Med. 24 (2013) 71-84.

[65] A. Ribeiro, F.J. Arias, J. Reguera, M. Alonso, J.C. Rodríguez-Cabello, Influence of the amino-acid sequence on the inverse temperature transition of elastin-like polymers, Biophys. J. 97 (2009) 312-320.

[66] J.M. Silva, S.G. Caridade, R.R. Costa, N.M. Alves, T. Groth, C. Picart, R.L. Reis, J.F. Mano, $\mathrm{pH}$ responsiveness of multilayered films and membranes made of polysaccharides, Langmuir 31 (2015) 11318-11328.

[67] W.F. Liu, C.S. Chen, Engineering biomaterials to control cell function, Mater Today 8 (2005) 28-35.

[68] A.J. García, Get a grip: integrins in cell-biomaterial interactions, Biomaterials 26 (2005) 7525-7529.

[69] S.M. Oliveira, N.M. Alves, J.F. Mano, Cell interactions with superhydrophilic and superhydrophobic surfaces, J. Adhes. Sci. Technol. 28 (2014) 843-863.

[70] C. Picart, R. Elkaim, L. Richert, F. Audoin, Y. Arntz, M. Da Silva Cardoso, P. Schaaf, J.C. Voegel, B. Frisch, Primary cell adhesion on RGD-functionalized and covalently crosslinked thin polyelectrolyte multilayer films, Adv. Funct. Mater 15 (2005) 83-94.

[71] K. Rochlin, S. Yu, S. Roy, M.K. Baylies, Myoblast fusion: when it takes more to make one, Dev. Biol. 341 (2010) 66-83.

[72] N. Osses, E. Brandan, ECM is required for skeletal muscle differentiation independently of muscle regulatory factor expression, Am. J. Physiol. Cell Physiol. 282 (2002) C383-C394.

[73] P.-Y. Wang, H. Thissen, W.-B. Tsai, The roles of RGD and grooved topography in the adhesion, morphology, and differentiation of $\mathrm{C} 2 \mathrm{C} 12$ skeletal myoblasts, Biotechnol. Bioeng 109 (2012) 2104-2115. 